VANESSA CRISTINNE VICTOR RABAQUIM

\begin{abstract}
DESENVOLVIMENTO E USO DE APLICATIVO MÓVEL PARA MONITORAMENTO DA OCORRÊNCIA DE MORDEDURAS POR MORCEGOS HEMATÓFAGOS E SUSPEITAS DE RAIVA EM HERBÍVOROS NO ESTADO DE SÃO PAULO
\end{abstract}




\section{DESENVOLVIMENTO E USO DE APLICATIVO MÓVEL PARA MONITORAMENTO DA OCORRÊNCIA DE MORDEDURAS POR MORCEGOS HEMATÓFAGOS E SUSPEITAS DE RAIVA EM HERBÍVOROS NO ESTADO DE SÃO PAULO}

Dissertação apresentada ao Programa de Pós-Graduação em Epidemiologia Experimental Aplicada às Zoonoses da Faculdade de Medicina Veterinária e Zootecnia da Universidade de São Paulo para a obtenção do título de Mestre em Ciências

\section{Departamento:}

Departamento de Medicina Veterinária Preventiva e Saúde Animal.

Área de concentração:

Epidemiologia Experimental Aplicada às Zoonoses.

Orientador:

Prof. Dr. Ricardo Augusto Dias

São Paulo 
Autorizo a reprodução parcial ou total desta obra, para fins acadêmicos, desde que citada a fonte.

DADOS INTERNACIONAIS DE CATALOGAÇÃO NA PUBLICAÇÃO

(Biblioteca Virginie Buff D’Ápice da Faculdade de Medicina Veterinária e Zootecnia da Universidade de São Paulo)

T. 3567

FMVZ

Rabaquim, Vanessa Cristinne Victor

Desenvolvimento e uso de aplicativo móvel para monitoramento da ocorrência de mordeduras por morcegos hematófagos e suspeitas de raiva em herbívoros no Estado de São Paulo. / Vanessa Cristinne Victor Rabaquim. -- 2017.

$61 \mathrm{f}$ : : il.

Dissertação (Mestrado) - Universidade de São Paulo. Faculdade de Medicina Veterinária e Zootecnia. Departamento de Medicina Veterinária Preventiva e Saúde Animal, São Paulo, 2017.

Programa de Pós-Graduação: Epidemiologia Experimental Aplicada às Zoonoses.

Área de concentração: Epidemiologia Experimental Aplicada às Zoonoses.

Orientador: Prof. Dr. Ricardo Augusto Dias.

1. Android®. 2. Aplicativo móvel. 3. LiveCode®. 4. Sistema de notificação. 5. Raiva. I. Título. 
IImo(a). Sr(a).

Responsável: Ricardo Augusto Dias

Área: Epidemiologia Experimental Aplicada As Zoonoses

Ricardo Augusto Dias (orientador)

Título do projeto: "DESENVOLVIMENTO E USO DE APLICATIVO MÓVEL PARA MONITORAMENTO DA OCORRÊNCIA DE MORDEDURAS POR MORCEGOS HEMATÓFAGOS E SUSPEITAS DE RAIVA EM HERBÍVOROS NO ESTADO DE SÃO PAULO.".

\section{Parecer Consubstanciado da CEUA FMVZ/USP}

A Comissão de Ética no Uso de Animais da Faculdade de Medicina Veterinária e Zootecnia da Universidade de São Paulo, na reunião de 04/10/2017, ANALISOU e APROVOU o protocolo de estudo acima referenciado. A partir desta data, é dever do pesquisador:

1. Comunicar toda e qualquer alteração do protocolo.

2. Comunicar imediatamente ao Comitê qualquer evento adverso ocorrido durante o desenvolvimento do protocolo.

3. Os dados individuais de todas as etapas da pesquisa devem ser mantidos em local seguro por 5 anos para possível auditoria dos órgãos competentes.

4. Relatórios parciais de andamento deverão ser enviados anualmente à CEUA até a conclusão do protocolo.

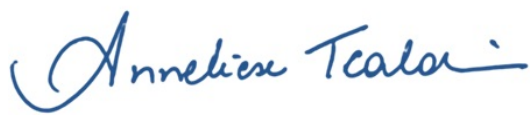

Profa. Dra. Anneliese de Souza Traldi Presidente da Comissão de Ética no Uso de Animais de São Paulo

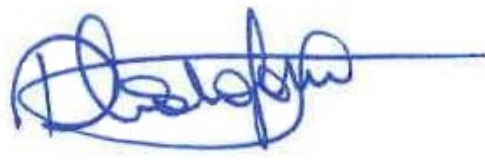

Claudia Madalena Cabrera Mori Vice-Presidente

Faculdade de Medicina Veterinária e Zootecnia da Universidade de São Paulo 


\section{CERTIFIED}

We certify that the Research "Development and use of a mobile application to monitor the occurrence of bites by hematophagous bats and suspected rabies in herbivores in the state of São Paulo.", protocol number CEUAx 8626040917, under the responsibility Ricardo Augusto Dias, agree with Ethical Principles in Animal Research adopted by Ethic Committee in the Use of Animals of School of Veterinary Medicine and Animal Science (University of São Paulo), and was approved in the meeting of day October $04,2017$.

Certificamos que o protocolo do Projeto de Pesquisa intitulado "DESENVOLVIMENTO E USO DE APLICATIVO MÓVEL PARA MONITORAMENTO DA OCORRÊNCIA DE MORDEDURAS POR MORCEGOS HEMATÓFAGOS E SUSPEITAS DE RAIVA EM HERBÍVOROS NO ESTADO DE SÃO PAULO.", protocolado sob o CEUAx nㅇ 8626040917, sob a responsabilidade de Ricardo Augusto Dias, está de acordo com os princípios éticos de experimentação animal da Comissão de Ética no Uso de Animais da Faculdade de Medicina Veterinária e Zootecnia da Universidade de São Paulo, e foi aprovado na reunião de 04 de outubro de 2017.

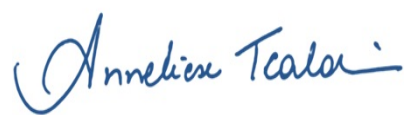

Profa. Dra. Anneliese de Souza Traldi Presidente da Comissão de Ética no Uso de Animais Faculdade de Medicina Veterinária e Zootecnia da Universidade Faculdade de Medicina Veterinária e Zootecnia da Universidade de São Paulo

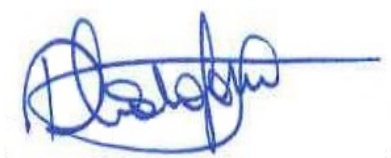

Claudia Madalena Cabrera Mori Vice-Presidente de São Paulo 
FOLHA DE AVALIAÇÃO

Autor: RABAQUIM, Vanessa Cristinne Victor

Titulo: Desenvolvimento e uso de Aplicativo Móvel para Monitoramento da Ocorrência de Mordeduras por Morcegos Hematófagos e Suspeitas de Raiva em Herbívoros no Estado De São Paulo

Dissertação apresentada ao Programa de Pós-Graduação em Epidemiologia Experimental Aplicada às Zoonoses da Faculdade de Medicina Veterinária e Zootecnia da Universidade de São Paulo para a obtenção do título de Mestre em Ciências

DATA: 1

\section{BANCA EXAMINADORA}

Prof. Dr:

Instituição: Julgamento:

Prof. Dr:

Instituição: Julgamento:

Prof. Dr: Instituição: Julgamento: 
Dedico este trabalho a minha família e aos meus monstrinhos. 


\section{AGRADECIMENTOS}

\section{A Casa de Cosme e Damião e aos meus guias espirituais.}

A minha família por sempre estarem comigo, me deixando louca por muitas vezes, mas sem dúvida são o meu porto seguro.

Ao meu primo Rafael Rabaquim que me ajudou muito com a linguagem de programação.

Aos meus monstrinhos, Carolina Donola e Anderson Antônio, uma família muito maluquinha que o coração escolheu, que aguentam todos os meus surtos e que com uma mesa, uma boa música, um abraço e um copo de whisky somados a uma boa conversa, todos os problemas do mundo tornam-se minúsculos.

A uma amiga inesperada nesta jornada, Cássia Ikuta que me ensinou muito, e que sem dúvida vou continuar aprendendo muito com ela e por muito tempo. "Nós contra o mundo!!!!", uma mesa, uma boa comida, uma boa cerveja e muitas risadas para solucionar os grandes dilemas.

Aos Professores do VPS, por sempre terem sido solícitos.

Ao meu orientador Prof. Dr. Ricardo Dias que aceitou me orientar, e que mesmo com o longo caminho nunca desistiu de me orientar.

Ao Prof. Dr. Fernando Ferreira, sempre solicito e disposto a ajudar.

Ao Prof. Dr. José Soares, pelas inúmeras conversas e risadas.

À Prof. Dr. Evelise Telles, pela compreensão e pelos ensinamentos.

Ao Prof. Dr. José Grisi, pela ajuda com a linguagem de programação do servidor.

Ao Prof. Dr. Marcelo Labruna, pela paciência em me escutar e por todo o apoio necessário.

Aos funcionários do VPS por todos os momentos.

A Carlota (Carol), por ser uma grande educadora, por apoiar nos momentos de crise com todo seu conhecimento e ser um exemplo com seu crescimento pessoal. 
"...O próximo grande salto evolutivo da humanidade será a descoberta de que cooperar é melhor que competir..."

(Professor Pietro Ubaldi) 


\section{RESUMO}

RABAQUIM, V.C.V. Desenvolvimento e uso de aplicativo móvel para Monitoramento da ocorrência de mordeduras por morcegos hematófagos e suspeitas de raiva em herbívoros no Estado de São Paulo. [Development and use of a mobile application to monitor the occurrence of bites by hematophagous bats and suspected rabies in herbivores in the state of São Paulo]. 2017. $61 \mathrm{f}$. Dissertação (Mestrado em Ciências) - Faculdade de Medicina Veterinária e Zootecnia, Universidade de São Paulo, São Paulo, 2017.

O monitoramento da população animal é um instrumento imprescindível para o controle de zoonoses e outras doenças. Com o avanço tecnológico, em termos de comunicação, houve o aumento no desenvolvimento de aplicativos móveis. Este trabalho tem com o objetivo desenvolver um aplicativo móvel para o sistema operacional Android ${ }^{\circledR}$ com o propósito de otimizar o sistema de notificação de animais espoliados por morcegos e casos de suspeitas de raiva. Sendo utilizado para o desenvolvimento do aplicativo o Software LiveCode ${ }^{\circledR}$. O Aplicativo é capaz de se conectar ao banco de dados em um servidor através da Internet móvel ou wi fi, e permite ao proprietário notificar a incidência de mordedura por morcego ou suspeita de raiva no rebanho, e ao médico veterinário visualizar e modificar os dados enviados pelo proprietário da sua região. Diante dos dados obtidos neste trabalho, conclui-se que o aplicativo atende aos objetivos propostos de coletar dados de notificação e otimizar o sistema de notificação. A baixa adesão ao aplicativo, devido a ausência de acesso a Internet pelos proprietários, sugere a necessidade de modificar o sistema de comunicação do aplicativo com o banco de dados.

Palavra-chave: Android ${ }^{\circledR} ;$ Aplicativo Móvel; LiveCode ${ }^{\circledR}$; Sistema de Notificação; Raiva. 


\section{ABSTRAT}

RABAQUIM, V.C.V. Development and use of a mobile application to monitor the occurrence of bites by hematophagous bats and suspected rabies in herbivores in the state of São Paulo [Desenvolvimento e uso de aplicativo móvel para Monitoramento da ocorrência de mordeduras por morcegos hematófagos e suspeitas de raiva em herbívoros no Estado de São Paulo]. 2017. 61 f. Dissertação (Mestrado em Ciências) Faculdade de Medicina Veterinária e Zootecnia, Universidade de São Paulo, São Paulo, 2017.

Monitoring of the animal population is an essential tool for the control of zoonoses and other diseases. With the technological advancement, in terms of communication, there has been an increase in the development of mobile applications. This work aims to develop a mobile application for the Android $囚$ operating system for the purpose of optimizing the notification system of bat-bitten animals and suspected rabies cases. LiveCode® Software is used for the development of the application. The application is able to connect to the database on a mobile Internet or wi fi, and allows the owner to report the incidence of bat bitten or suspected rabies in the herd, and to the veterinarian viewing and modifying the data sent by the owner of your region. Based on the data obtained in this work, it is concluded that the application meets the proposed objectives of collecting notification and optimizing the notification system. The low adherence to the application, due to the absence of Internet access by the owners, suggests the need to modify the communication system of the application with the database.

Keyword: Android ${ }^{\circledR}$; Mobile Application; LiveCode ${ }^{\circledR}$; Notification System; Rabies. 


\section{SUMÁRIO}

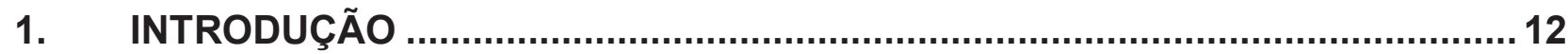

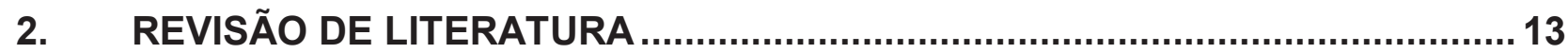

2.1. USO DE TECNOLOGIA MOVEL NA VIGILÂNCIA EPIDEMIOLOGICA ................ 13

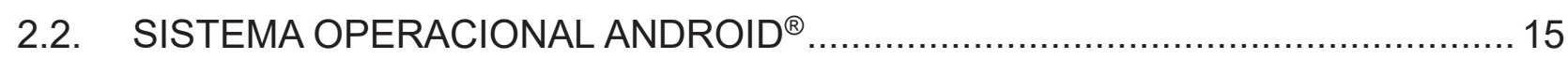

2.2.1. Android ${ }^{\circledR}$ Source Development Kit (SDK) ................................................... 18

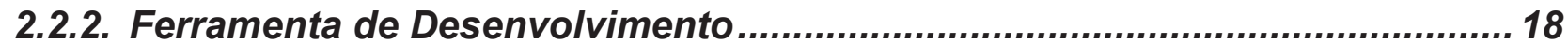

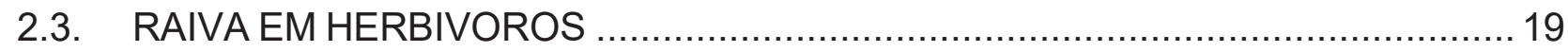

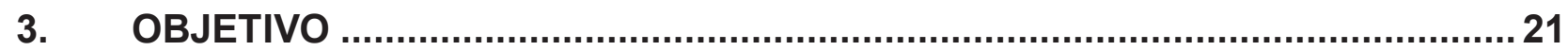

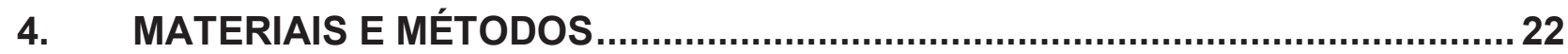

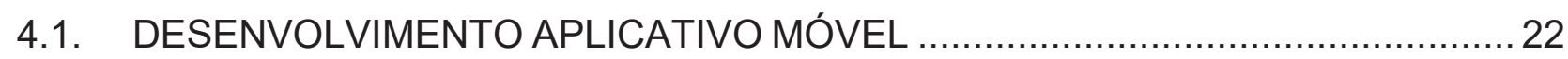

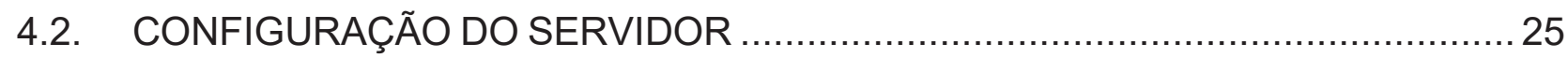

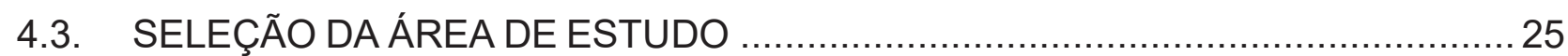

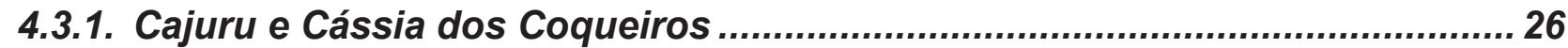

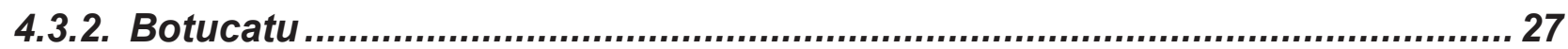

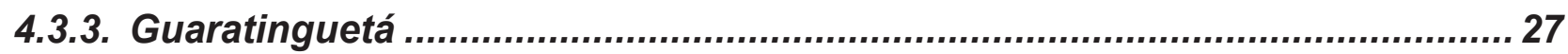

4.4. DESENVOLVIMENTO DE MAPAS DAS PROPRIEDADES SELECIONADAS .....28

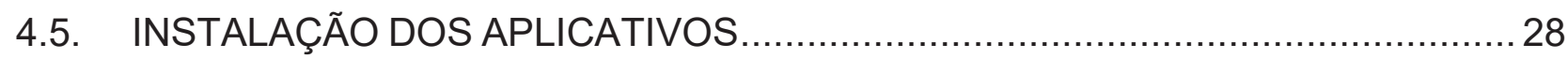

5. RESULTADOS

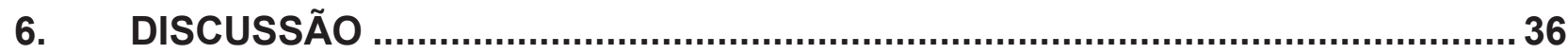

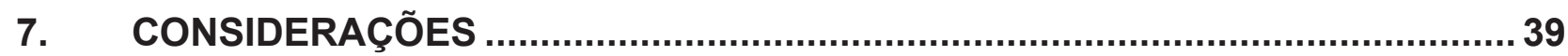

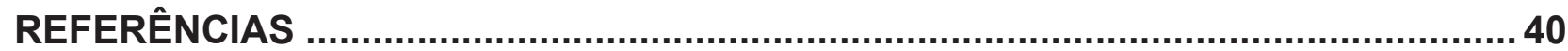

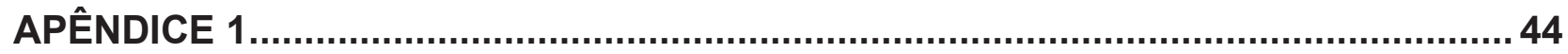

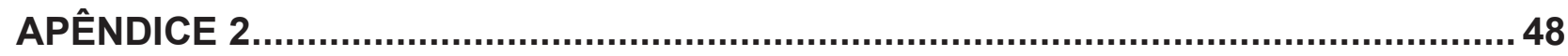

APÊNDICE 3 


\section{INTRODUÇÃO}

Segundo Alexander Langmuir (1963) a definição de vigilância epidemiológica é "observação contínua da distribuição e tendências da incidência de doenças mediante a coleta sistemática, consolidação e avaliação de informes de morbidade e mortalidade, assim como de outros dados relevantes, e a regular disseminação dessas informações a todos os que necessitam conhecê-la".

O monitoramento da população animal em uma determinada região é, portanto, um instrumento imprescindível para o controle de zoonoses e outras doenças. $\mathrm{Na}$ cadeia epidemiológica da raiva em ambiente rural, a transmissão do vírus para herbívoros de interesse econômico ocorre, principalmente, pelo morcego hematófago Desmodus rotundus. Dado que a raiva é uma antropozoonose de alta mortalidade com grande impacto econômico, é de notificação compulsória (OIE, 2017).

A notificação da ocorrência de espoliação por morcegos hematófagos, e casos suspeitos de raiva, é indispensável para o controle da doença em animais herbívoros de interesse econômico (MAPA, 2005).

Os avanços tecnológicos, em termos de comunicação, evoluíram exponencialmente nas últimas décadas, e a facilidade de acesso a estas tecnologias pela população ocasionou uma alta demanda por dispositivos móveis. Adicionalmente, houve também melhoria ao acesso à Internet móvel, gerando o estímulo ao desenvolvimento de aplicativos que facilitam a comunicação, além de proporcionar um acesso rápido a informação (DORODA, 2012).

Em um processo de associação do avanço tecnológico à definição de vigilância epidemiológica, identifica-se a necessidade de tecnificação do sistema de notificação da raiva e um monitoramento da população de morcegos da área rural. 


\section{REVISÃO DE LITERATURA}

\subsection{USO DE TECNOLOGIA MOVEL NA VIGILÂNCIA EPIDEMIOLOGICA}

Segundo a OMS (2000), para o controle efetivo de doenças transmissíveis, é necessária uma resposta efetiva do sistema de vigilância de doenças. A otimização deste sistema de vigilância vem sendo empregada em diversos países com a vigilância participativa, onde o cidadão local é voluntario na notificação de alterações do padrão epidemiológico de doenças de interesse para saúde pública (BRASIL, 2017c)

Outra forma de vigilância empregada na maioria dos países é a vigilância comunitária, onde um representante do órgão de saúde local, denominado como agente comunitário ou agente de saúde, é instruído a reportar qualquer alteração no padrão epidemiológico na região, a qual esta sob sua fiscalização (COLOMBIA, 2012; OUM, 2005)

A introdução de ferramentas, que incorporem a vigilância participativa e vigilância comunitária, vem sendo utilizada como mecanismo complementar aos métodos tradicionais de vigilância, como o uso de "aplicações" que auxiliem no processo de notificação e o uso do geoprocessamento para monitoramento de surtos (BRASIL, 2017c; COLOMBIA, 2012).

O uso de tecnologia móvel está cada vez mais integrado ao cotidiano da população. $\mathrm{O}$ avanço digital promoveu um aumento no desenvolvimento e produção de smartphones e tablets, facilitando o seu acesso. A expansão tecnológica proporcionou o desenvolvimento de aplicativos móveis que podem ser utilizados em diversas áreas, por exemplo, monitoramento de indicadores e de condições de saúde das populações (DORODA, 2012).

A evolução deste desenvolvimento, voltado para área da saúde, evoluiu progressivamente nos últimos anos. O uso de recursos de Short Message Service (SMS) do dispositivo móvel é costumeiramente utilizado em aplicativos desenvolvidos para regiões de escasso acesso à Internet móvel e fixa, ou regiões de baixo poder aquisitivo (CÁCERES, et al., 2016).

Em 2008, após os surtos de Chikungunya em Madagascar, o Ministério da Saúde e o Instituto Pasteur do país desenvolveram um sistema de detecção precoce de 
surtos. O sistema de notificação foi baseado em SMS criptografados, de forma que os médicos sentinelas enviavam dados pessoais dos pacientes, como idade, sexo e sinais clínicos, e relatavam casos de febre, malária, diarreia e influenza. No período de um ano o sistema de notificação identificou precocemente cinco surtos, totalizando 26.669 casos registrados (RANDRIANASOLO et al., 2010).

A partir deste modelo por SMS, Pascoe e colaboradores (2012) desenvolveram o District Health Information System 2 (DHIS2), um aplicativo livre, adaptável a qualquer dispositivo móvel que estivesse habilitado para Java. Este sistema envia as informações coletadas em forma de SMS para o servidor, que incorporava estas informações ao banco de dados. O DHIS2 foi utilizado na Tanzânia para notificação de mortalidade infantil. Após três meses de uso, a frequência de notificação de casos de mortes aumentou de $50 \%$ para $89 \%$.

Em Guinea-Bissau o "SMS reporting" foi utilizado para avaliar a distribuição de suspeitas ou novos casos de Ebola. O sistema funcionava a base de SMS sem a necessidade de acesso à Internet. Diariamente, os agentes da saúde treinados recebiam uma mensagem onde poderiam responder de zero ao infinito, sendo zero nenhum caso ou suspeita (CÁCERES, et al., 2016).

Asangansi e Braa (2009) implantaram na Nigéria e na Índia o aplicativo $m$-Health para otimizar o sistema de informação em saúde, tanto em âmbito distrital como nacional. Nos estados Katsina e Yobe, no norte da Nigéria são caracterizados pelo baixo nível de acesso ao serviço de saúde apresentando um maior número de incidência de poliomielite e sarampo. Asangansi e Braa (2009) optaram por treinar profissionais de saúde de 34 centros de atendimento, pois o acesso à tecnologia nestes estados é escasso.

$\mathrm{Na}$ Índia, o Sistema de Informação da Sociedade para a Saúde está implementando o Sistema Distrital de Informações de Saúde em formato backbone ${ }^{1}$ em cinco estados. Um dos principais achados foi a melhora na notificação, além de evitar os grandes deslocamentos entre cidades para relatar os dados coletados (ASANGANSI; BRAA, 2009).

Ainda sobre o uso de aplicativos voltados para saúde, o desenvolvimento de sistemas dependentes de transferência de dados pela Internet móvel ou fixa, são

${ }^{1}$ Termo utilizado para identificar a rede principal pela qual os dados de todos os clientes da Internet passam. É a "espinha dorsal da Internet". 
aplicáveis em regiões que dispunham de poder aquisitivo maior, ou regiões com amplo acesso à Internet (STAIR; REYNOLDS, 2016).

Em 2014, o Training Programs in Epidemiology and Public Health Intervetions Network (TEPHINET), juntamente à Secretaria de Vigilância em Saúde do Ministério da Saúde brasileiro e ao Centers for Disease, Prevention and Control (CDC), criou um aplicativo no software livre Epi Info 7. O aplicativo foi instalado em tablets com acesso à Internet móvel, entregues para profissionais em dez unidades de saúde, e conforme a inserção de dados, os mesmos eram enviados em tempo real. O sistema foi utilizado em Fortaleza (CE) durante a Copa do Mundo FIFA no Brasil, para detectar possíveis surtos em eventos de massa como uma estratégia de vigilância ativa (GARCIA et al., 2016).

Apesar dos bons resultados, no sistema de vigilância em doenças infecciosas em humanos, o uso de aplicativo móvel é pouco explorado como medida de intervenção em vigilância epidemiológica veterinária.

Robertson e colaboradores (2010) implantaram no Sri Lanka um Sistema de Vigilância e Análise de Doenças Infecciosas, criado com base no software livre EpiSurveyor. Com a premissa de auxiliar na detecção precoce de doenças infecciosas em frangos, bovinos e bubalinos. O aplicativo foi instalado em 40 dispositivos móveis e entregue aos veterinários de campo que notificaram semanalmente uma média de 2 propriedades/ veterinário (ROBERTSON et al., 2010).

O agronegócio brasileiro dispõe de um método de monitoramento móvel chamado Agriness S2. O sistema é utilizado em palm top, de forma que os funcionários de granjas de suinocultura preenchiam dados como mortalidade, natalidade, alimentação e medicação destes animais (GRESSULLI, 2016).

O uso de aplicativos móveis para aprimorar o sistema de vigilância participativa é pouco explorado, porém, é melhor utilizado na vigilância comunitária pela facilidade de treinar todos os usuários da aplicação.

\subsection{SISTEMA OPERACIONAL ANDROID ${ }^{\circledR}$}

O sistema operacional Android ${ }^{\circledR}$ liderou o mercado de telefonia móvel no mundo pela primeira vez em 2014. Nos anos seguintes, teve um crescimento continuo e 
acima do esperado para o mercado, atingindo $68,67 \%$ do mercado de telefonia móvel no Brasil (NETMARKET, 2016).

Segundo os dados da Amostra de Domicilio do IBGE (2013) 57,3\% da população brasileira, acessavam a Internet por meio de telefones móveis ou tablet.

A Associação Brasileira de Marketing Rural \&Agronegócio (ABMR\&A) traçou o perfil comportamental do produtor rural, caracterizando $58 \%$ da população rural como informados das novas tecnologias e usuários de dispositivos móveis e serviços de Internet. Por outro lado, 42\%, desta população preservaram hábitos antigos e possueíam maior resistência a utilização de novos recursos (ABMR\&A, 2014).

A facilidade do acesso à Internet através de dispositivos móveis e a importância do Android ${ }^{\circledR}$ justificam o crescimento no mercado de aplicativos móveis para este sistema operacional.

Pertencente ao Google ${ }^{\circledR}$ e à Open Handset Alliance (OHA), o Android ${ }^{\circledR}$ é um sistema open source desenvolvido com base no Linux para dispositivos móveis. $O$ Android $^{\circledR}$ usa Java ${ }^{\circledR}$ como linguagem de programação padrão, porém a linguagem C/C++ pode ser usada para desenvolver aplicativos nativos (FARIA, 2016; ANDROID, 2016).

O desenvolvedor tem total acesso aos códigos fontes por ser uma plataforma de código aberto, o que permite a compreensão do funcionamento do sistema operacional (ANDROID DEVELOPER, 2016).

O Android ${ }^{\circledR}$ possui várias camadas com funcionalidade e propósitos específicos, sendo que esta disposição de camadas visa melhorar o desempenho do dispositivo móvel (GARGENTA, 2011). (Figura 1) 
Figura 1- Camadas do Sistema Operacional Android ${ }^{\circledR}$

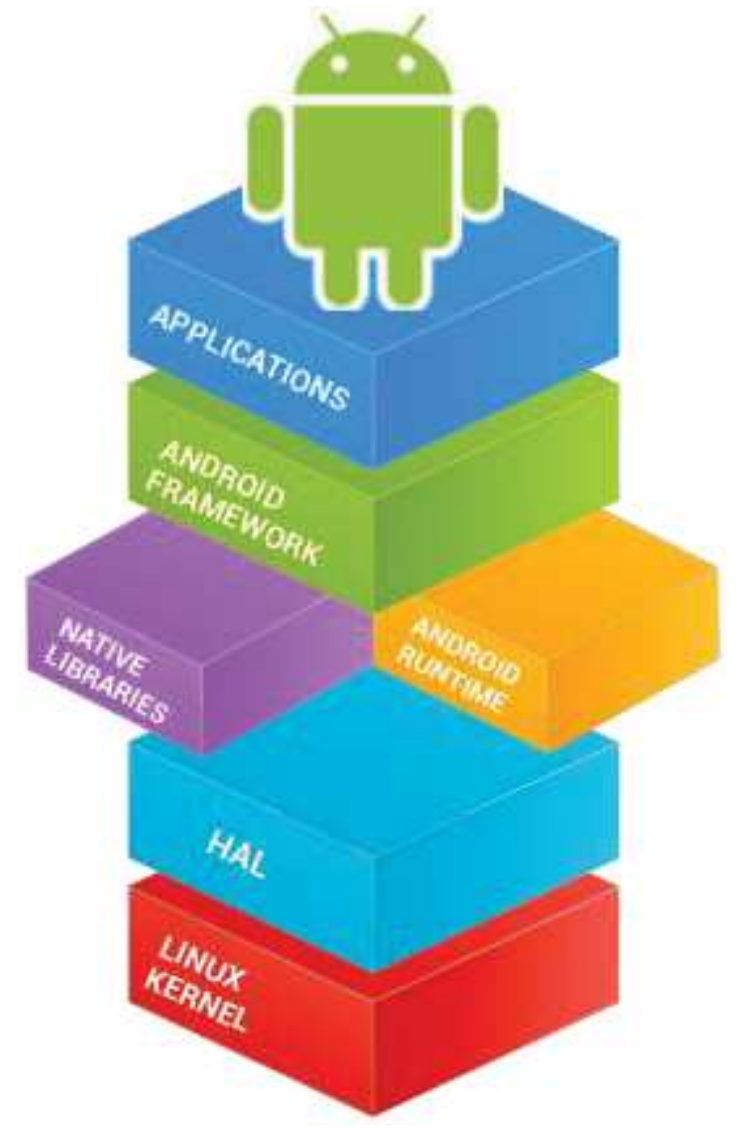

Fonte: (ANDROID, 2016)

O desenvolvimento do Android ${ }^{\circledR}$ manteve o núcleo Linux. O Kernel é a camada de abstração entre o dispositivo e o software contendo diversos recursos necessários para execução de aplicações, como gerenciamento de memória, protocolos de redes, módulo de segurança de infraestrutura (FARIA, 2016; GARGENTA, 2011).

A camada de abstração de hardware (HAL) fornece um método padrão para o desenvolvimento de ganchos de software entre a plataforma Android ${ }^{\circledR}$ e seu hardware (ANDROID, 2016).

A camada de biblioteca nativa encontramos várias bibliotecas em $\mathrm{C} / \mathrm{C}++$ utilizadas pelo Android ${ }^{\circledR}$, como as multimídias, funções para browser, gráficos, aceleração de hardware e funções de acessos ao banco de dados SQLite (FARIA, 2016; GARGENTA, 2011).

O Android ${ }^{\circledR}$ Runtime é responsável pela criação e gerenciamento dos módulos responsáveis pela execução das aplicações. Esta camada é gerenciada pela máquina virtual Dalvik desenvolvida diretamente para o Android $^{\circledR}$, portanto, gerando um código 
distinto do comumente compilado pelo Java. O Java para Android ${ }^{\circledR}$ possui uma camada extra chamada de Dex bytecode, funcionando como um otimizador duas vezes mais eficiente em armazenamento que reduz pela metade a memória exigida para execução de cada aplicação (GARGENTA, 2011; MEDNIEKS et al., 2012).

A camada de framework é a camada responsável por fornece as ferramentas para o desenvolvedor, ou seja, um conjunto de serviços e sistemas que gerenciam os recursos de software provido pelo Android ${ }^{\circledR}$ (GARGENTA, 2011).

As "aplicações" corresponde à camada responsável por armazenar os aplicativos do Android $^{\circledR}$, os quais são distribuídos em um pacote de arquivos com a extensão APK, que possui duas partes essenciais: 1- Parte executável Dalvik- código compilado para ser executado na plataforma Android ${ }^{\circledR}$. 2- Resource- tudo que contem no aplicativo que não é executável no código, como imagens, pacote de linguagens, arquivos XML. (GARGENTA, 2011).

\subsubsection{Android ${ }^{\circledR}$ Source Development Kit (SDK)}

O Google ${ }^{\circledR}$ disponibiliza para usuários e desenvolvedores um pacote de dados para criação de seus próprios aplicativos móveis, este pacote de dados Source Development Kit (SDK) permite que o usuário possa criar um aplicativo em um Software de desenvolvimento de sua preferência e com auxílio do SDK converter este projeto em APK compatível com o Android ${ }^{\circledR}$ (ABLESON, 2012).

\subsubsection{Ferramenta de Desenvolvimento}

O Live Code ${ }^{\circledR}$ é uma plataforma de programação multi-plataformas, capaz de implantar a mesma base de códigos para várias plataformas como iOS, Android ${ }^{\circledR}$, Mac, Windows, Linux, Servidores e opções de HTML5 (LIVE CODE, 2016).

Esta plataforma de trabalho fornece recursos que permite interagir de forma rápida e continua proporcionando um desenvolvimento da linha de comando com maior velocidade (LIVE CODE, 2016). 
O Live Code ${ }^{\circledR}$ possui uma linguagem de programação simples e memorável que se aproxima da forma de falar e pensar da língua inglesa. Isso significa que é possível escrever 90\% menos códigos em comparação as linguagens tradicionais de programação (LIVE CODE, 2016).

O Live Code ${ }^{\circledR}$ possui uma biblioteca de códigos que facilitam a criação de linhas de comando, além de permitir a criação de novos códigos (LIVE CODE, 2016).

\subsection{RAIVA EM HERBIVOROS}

O morcego Desmodus rotundus (DR) pertence à ordem Chiroptera, à família Phyllostomidae e possui uma ampla distribuição na América Latina. É a espécie hematófaga mais abundante, além de ser a mais estudada devido à grande perda econômica causada pelo repasto sanguíneo em herbívoros de interesse econômico (HIE) e pela possibilidade de transmissão do vírus da raiva (REIS et al. 2007).

O DR forma colônias que variam de 10 a 50 animais, porém, agrupamentos com mais de 100 habitantes são comuns em locais onde não há o controle destes animais (UIEDA, 1987; GREENHALL et al., 1983). Esta espécie é facilmente adaptável às modificações introduzidas pelo homem no ambiente, capaz de utilizar abrigos diurnos em cavidades naturais ou artificiais (GREENHALL et al., 1983).

Os morcegos hematófagos representam o melhor e mais eficiente veículo de propagação da raiva para herbívoros, já que os mesmos agridem diariamente estes animais (UIEDA, 1987). A raiva é uma zoonose infecto-contagiosa descrita desde 2000 a.C. É causada pelo vírus do gênero Lyssavírus, transmitida pela saliva dos animais infectados através da mordedura ou lambedura destes, afetando predominantemente mamíferos domésticos e selvagens (BRASIL, 2006).

A infecção pelo vírus da raiva tem progressão para óbito em $100 \%$ dos casos, causando um prejuízo econômico estimado em centenas de milhões de dólares. A perda econômica não está relacionada somente ao óbito animal, mas também aos gastos com vacinação de rebanhos e com o tratamentos pós-exposição de pessoas que estiveram em contato com os animais suspeitos (MAPA, 2005).

Além do prejuízo econômico causado pela transmissão da raiva, a mordedura do DR pode gerar outros danos, como anemia progressiva devido à espoliação 
contínua, risco potencial da transmissão de outros vírus associados à espoliação por morcegos, e infecção secundária pelas lesões causadas pelo repasto sanguíneo (MAPA, 2005).

Em 1966, o Ministério da Agricultura, por meio da Divisão de Defesa Sanitária Animal, instituiu o Plano de Combate à Raiva dos Herbívoros, que atualmente se denomina Programa Nacional de Controle da Raiva dos Herbívoros (PNCRH), executado pelo Departamento de Saúde Animal (DSA), do Ministério da Agricultura, Pecuária e Abastecimento (MAPA) (MAPA, 2005).

A raiva é uma doença de notificação compulsória, ou seja, cabe ao proprietário notificar imediatamente o Serviço Veterinário Oficial (SVO) a suspeita de casos de raiva. Assim como, a presença de animais com marcas de espoliação por morcego hematófago e existência de abrigos desses morcegos na propriedade (OIE, 2017; MAPA, 2005).

A partir da notificação da suspeita de raiva em HIE, como também da notificação de espoliação por morcego, o SVO atende rapidamente à notificação. Quando necessário, o material para diagnóstico laboratorial deverá ser coletado, e as medidas necessárias para o controle da população de morcegos DR na região deverão ser executadas (MAPA, 2005). 


\section{OBJETIVO}

Desenvolver um aplicativo móvel para o sistema operacional Android ${ }^{\circledR} \operatorname{com~o~}^{\circ}$ propósito de otimizar o sistema de notificação de animais espoliados e casos de suspeitas de raiva. Avaliar a aceitabilidade dos proprietários de área rural ao uso de aplicativo móvel para notificação 


\section{MATERIAIS E MÉTODOS}

\subsection{DESENVOLVIMENTO APLICATIVO MÓVEL}

Para elaboração do aplicativo móvel foi utilizado o Software Live Code ${ }^{\circledR}$, onde foi instalado o conversor Android ${ }^{\circledR}$ SDK e o Java Development Kit (JDK).

Para a programação do aplicativo foi utilizado linhas de comando com a linguagem de programação SQLite aceita pelo Live Code ${ }^{\circledR}$ (APÊNDICE 3).

O aplicativo foi dividido em dois ambientes diferentes, um para o proprietário, e outro para o veterinário (DIAGRAMA 1; FLUXOGRAMA 1, APÊNDICE 1). 


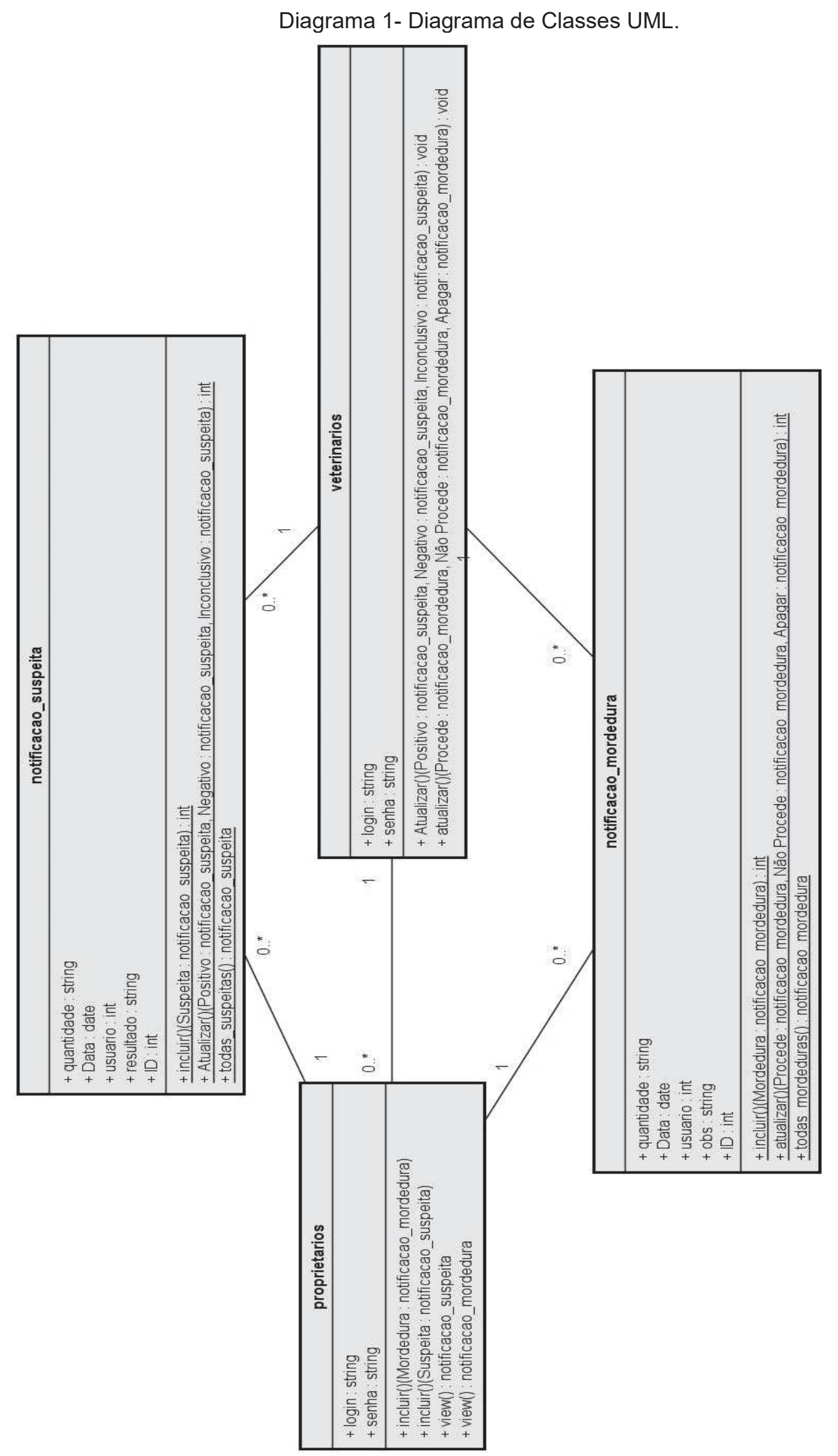

Fonte: (RABAQUIM, 2017). 
Fluxograma 1- Metodologia utilizada no desenvolvimento do aplicativo Android ${ }^{\circledR}$.

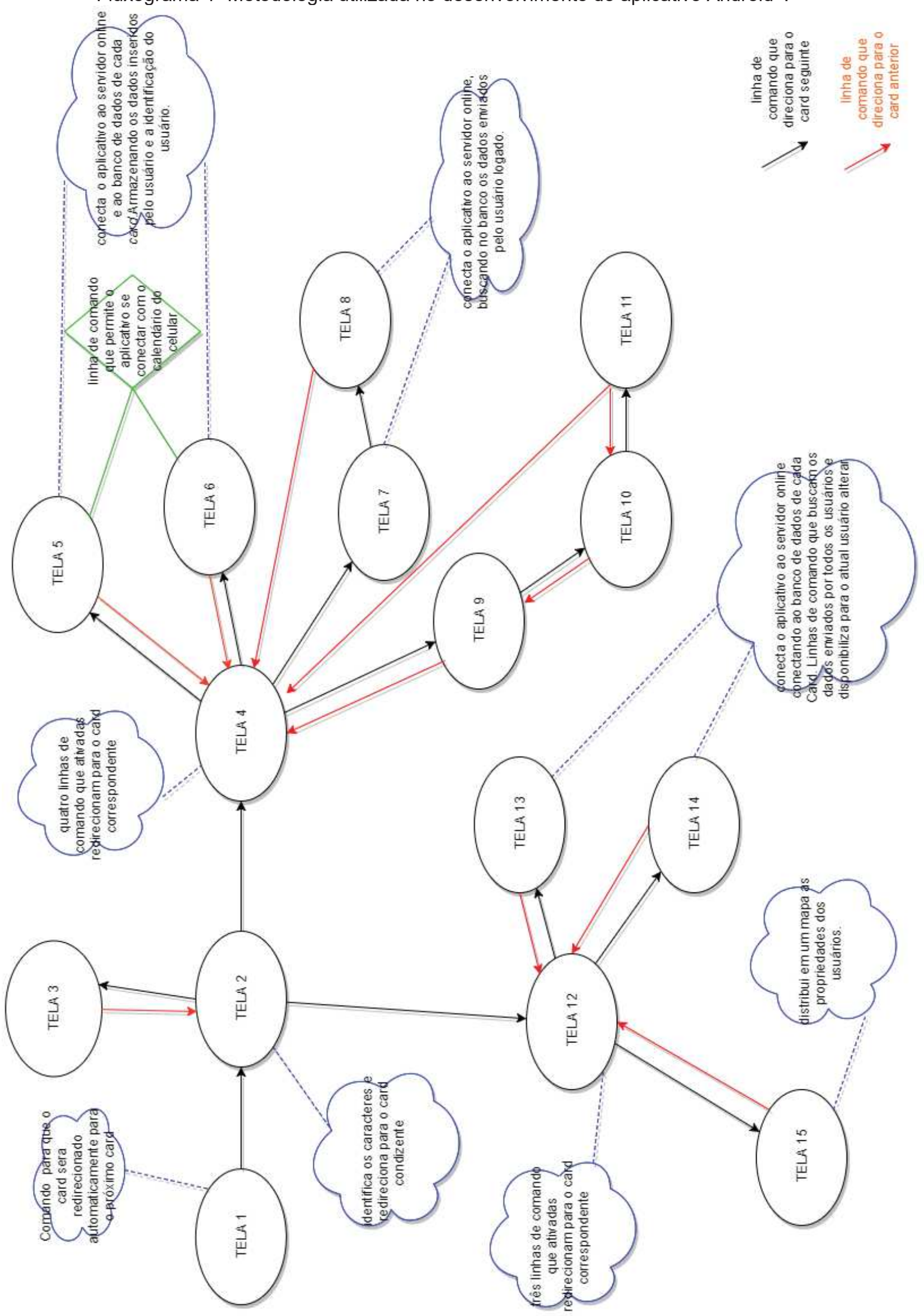

Fonte: (RABAQUIM, 2017). 


\subsection{CONFIGURAÇÃO DO SERVIDOR}

Um servidor online foi criado no serviço Nuvem USP, que possui uma porta de acesso pública, alterada por medida de segurança, para evitar o acesso de pessoas não relacionadas ao projeto.

O banco de dados do servidor foi criado a partir de linhas de comando onde foi utilizada a linguagem de programação SqL.

Para criação do servidor e do banco de dados, foi utilizado computador com sistema operacional Linux ${ }^{\circledR}$.

O banco de dados foi renomeado para "notificação" através de linhas de comando. A partir do banco de dados foram criadas duas tabelas: 1- "mordedura" composta pelos campos ID, Usuário, Mordedura e DataMordedura. 2- "suspeita" composta pelos campos ID, Usuário, Suspeita e DataSuspeita.

\subsection{SELEÇÃO DA ÁREA DE ESTUDO}

As áreas de estudo foram selecionadas previamente de acordo com informações de incidência de mordedura de morcegos hematófago em animais de interesse econômico fornecidas pela Coordenadoria de Defesa Agropecuária.

O acesso ao sinal de Internet móvel e ao sinal de Internet fixa foi considerado na seleção das propriedades nas regiões escolhidas para o trabalho.

As propriedades foram selecionadas de acordo com a proximidade aos abrigos de morcegos DR, fornecida pela Coordenadoria de Defesa Agropecuária através da comunicação verbal. 


\subsubsection{Cajuru e Cássia dos Coqueiros}

A mesorregião de Ribeirão Preto é uma das 15 mesorregiões do estado de São Paulo, composta por 66 municípios agrupados em sete microrregiões. É a mais rica do estado de São Paulo, e somente este ocupa o décimo primeiro maior Produto interno Bruto (PIB) do estado (BRASIL, 2017b).

De acordo com a Estimativa Populacional de 2016, a mesorregião tem 2.591.206 habitantes, sendo a terceira maior região do estado de São Paulo (BRASIL, 2017b).

Uma das microrregiões de Ribeirão Preto é a de Batatais, que possui uma área de 3.089,243 km² limítrofe com o estado de Minas Gerais, e é composta por seis municípios do estão de São Paulo, com estimativa populacional de 114.173 habitantes (BRASIL, 2017b).

A microrregião de Batatais possui municípios com status turísticos e municípios de interesse agropecuários, com estimativa de 98.027 mil cabeças de bovinos e 4 mil equinos (CAJURU, 2017).

Dentre os municípios da microrregião de Batatais, destaca-se os municípios de Cajuru com a segunda maior produção pecuária da região, e Cássia dos Coqueiros com a quinta maior produção pecuária e o maior centro turístico da região (BRASIL, 2016)

O município de Cajuru foi criado em 1866, e se localiza a 58 km de Ribeirão Preto, com clima temperado e culturalmente católica. A economia do município é baseada em agropecuária e agricultura. Com aproximadamente 23.170 mil bovinos e 1.329 equinos (BRASIL, 2016; CAJURU, 2017)

Com 23.371 habitantes, o município de Cajuru se desenvolveu baseado no agronegócio familiar com produção de cana-de-açúcar e pecuária. (IBGE, 2017b)

O município de Cássia dos Coqueiros foi oficializado em 1958. Uma cidade que se originou graças à produção de coqueiros agreste. É o município mais promissor da microrregião de Batatais, com uma população de 2.634, tendo como principal fonte de renda a agricultura, porêm seus produtores mantem uma pecuária de subsistência com uma estimativa de 12.338 mil bovinos e 594 equinos. (CÁSSIA DOS COQUEIROS, 2017; BRASIL, 2016)

A cidade possui inúmeras grutas e cachoeiras que se tornam fonte de renda para a cidade, devido ao grande potencial turístico (CÁSSIA DOS COQUEIROS, 2017; BRASIL, 2016) 


\subsubsection{Botucatu}

A mesorregião de Bauru é uma das 15 mesorregiões do estado de São Paulo, com uma área de $26.723,257 \mathrm{~km}^{2}$ dividida em cinco microrregiões, e sua população é estimada em 1.454.111 habitantes (BRASIL, 2016).

Uma de suas microrregiões é a de Botucatu, dividida em sete municípios que ocupam uma área de $4.381,834 \mathrm{~km}^{2}$, com população estimada de 207.410 habitantes. Possui um grande polo pecuário, com cerca de 183.195 bovinos e 3.530 equinos, que representa $19,93 \%$ e $36,82 \%$ da produção de bovinos e equinos respectivamente, do município de Botucatu (BRASIL, 2016).

Este município tem população estimada de 117.724 habitantes, com uma área territorial de $1.496 \mathrm{Km}^{2}$, e uma economia baseada em agropecuária, turismo e indústria (BRASIL, 2016; BOTUCATU, 2017).

\subsubsection{Guaratinguetá}

De origem Tupi-Guarani e fundada em 1630 Guaratinguetá faz parte da mesorregião do Vale do Paraíba e da microrregião de Guaratinguetá. Durante muitos anos o município de Guaratinguetá foi considerado um patrimônio religioso devido seus inúmeros eventos religiosos. (GUARATINGUETÁ, 2017)

Em 1885, a região passou a viver seu auge da cafeicultura tornando-se um marco na história com a estrada de ferro que liga São Paulo ao Rio de Janeiro (GUARATINGUETÁ, 2017).

No século $\mathrm{XX}$, o esgotamento das terras para produção de café obrigou os produtores a buscar novas fontes de renda, dentre elas destacaram-se a pecuária e 0 turismo (GUARATINGUETÁ, 2017).

A região do Vale do Paraíba desempenha papel importante na pecuária do Estado de São Paulo com aproximadamente 653.949 bovinos e 27.508 de equinos, destes, 43.633 bovinos e 567 equinos pertencentes ao município de Guaratinguetá. (GUARATINGUETÁ, 2017; BRASIL, 2016) 


\subsection{DESENVOLVIMENTO DE MAPAS DAS PROPRIEDADES SELECIONADAS}

As coordenadas das propriedades foram coletadas com um dispositivo Garmin GPSMap 64. Os dados deste dispositivo foram padronizados no Software Microsoft Excel $^{\circledR}$ e importado para o software livre ArcGis ${ }^{\circledR}$.

O banco de dados foi salvo em shapefile de pontos e sobreposto sobre um shapefile do território do estado de São Paulo.

\subsection{INSTALAÇÃO DOS APLICATIVOS}

A instalação foi feita manualmente por um integrante do projeto acompanhado de uma equipe de controle da Raiva do Estado de São Paulo (APÊNDICE 2).

Para transferência do arquivo .APK do aplicativo foi utilizado o sistema Bluetooth dos dispositivos móveis.

Os proprietários foram treinados para o uso do aplicativo, em visitas subsequentes em cada propriedade, no período de cinco dias.

Foram entregues cartões contendo o nome de usuário e a senha para acessar o aplicativo, com o telefone do responsável pelo projeto e o e-mail para contato.

Nas propriedades em que os responsáveis que possuíam smartphone não estavam presentes, o aplicativo foi enviado por e-mail com um manual de instalação e um vídeo de treinamento para o uso do aplicativo. Todo suporte de instalação foi ministrado por telefone.

Após a instalação e sensibilização os proprietários receberam semanalmente mensagens nos dispositivos móveis lembrando a importância de notificar. 


\section{RESULTADOS}

O aplicativo para sistema operacional Android $^{\circledR}$ foi desenvolvido com doze telas com dimensões flexíveis, capaz de se adequarem a todos os tamanhos de tela de dispositivos móveis. Sua capacidade de se conectar ao servidor, através da internet móvel ou wi fi, permite ao proprietário rural notificar a incidência de mordedura por morcego ou suspeita de raiva no rebanho, e ao veterinário visualizar as notificações dos usuários correspondentes a sua região possibilitando uma otimização no processo de controle da raiva rural.

O aplicativo funcionava exclusivamente com acesso à Internet. A capa do aplicativo possuía um temporizador de cinco segundos que transportava o usuário a página de login permitindo que o usuário preenchesse os campos com os dados fornecidos.

A partir dos dados de usuário, o aplicativo direcionava para o menu de proprietário ou o menu de veterinário (FLUXOGRAMA 2).

O menu de proprietário possuia quatro itens, sendo um dependente e três independentes. O primeiro ícone transportava o proprietário para a página de notificação de mordedura, que possuía um campo de preenchimento automático de data e um campo de preenchimento numérico para a quantidade de animais mordidos por morcego hematófago (FLUXOGRAMA 3).

A página de notificação de mordedura possuia um botão "enviar" que comunicava o aplicativo com o servidor enviando os dados preenchidos pelo proprietário.

O segundo item do menu proprietário encaminhava o usuário à página de notificação de suspeita de raiva, que possuía um campo de preenchimento automático de data, um campo travado com o número "1" para a notificação da quantidade de animais com suspeito e um botão "enviar" que comunicava o aplicativo com o servidor enviando os dados preenchidos pelo proprietário.

O terceiro ícone do menu proprietário era dependente dos dois primeiros, direcionando o proprietário para duas abas: mordedura e notificação que listavam as notificações do proprietário respectivamente.

O quarto item direcionava o proprietário a uma série de fotos de como identificar uma colônia, o morcego hematófago e uma mordedura de morcego hematófago. 
Quando um usuário entrava com o login de veterinário ele é direcionado para o menu veterinário, composto por três ícones sendo dois independentes e um dependente (FLUXOGRAMA 4)

O primeiro ícone direciona o veterinário à uma lista de todas as notificações de mordedura da região dele, sendo numeradas de um ao infinito. Esta aba permitia que o veterinário pudesse selecionar uma determinada notificação e atribuir a esta: procede, não procede e apagar.

O segundo ícone direcionava o veterinário a lista de todas as notificações de suspeita de raiva da região, sendo numeradas de um a infinito. Esta aba permitia que o veterinário pudesse selecionar uma determinada notificação e atribuir a esta: procede, não precede e apagar.

Ambos os ícones possuem um botão "enviar" que permitia a conexão do aplicativo com o servidor atualizando os dados alterados pelo usuário conectado.

O terceiro ícone continha um mapa do Google Maps ${ }^{\circledR} \mathrm{com}$ as propriedades da região do veterinário com nome, contato e endereço do proprietário.

O servidor em formato MySql era capaz de reconhecer os dados enviados pelo aplicativo e armazena-los. O Servidor ficava disponível na Nuvem USP com porta individual e específica.

As áreas de estudos ficaram estabelecidas como Cajuru e Cassia dos Coqueiros da microrregião de Batatais, São Manuel da microrregião de Botucatu e Guaratinguetá na microrregião de Guaratinguetá.

O aplicativo foi instalado em oito celulares de proprietários e um em celulare de veterinário, sendo cinco destes na microrregião de Batatais e quatro na microrregião de Botucatu. Na região de Guaratinguetá não foram instalados aplicativos devido à ausência de cobertura de telefonia móvel, na área rural, entretanto foram entregues fichas em papel para a notificação (MAPA 1).

Dos aplicativos instalados c foram por Bluetooth e três por instalação através do computador. Três aplicativos foram instalados em smartphones de parentes de proprietários que possuíam maior conhecimento sobre tecnologia.

Um proprietário notificou pelo aplicativo de maneira correta, cinco notificaram por mensagem em resposta as mensagens de lembrete e dois não se manifestaram, 0 veterinário não fez uso do aplicativo (TABELA 1; GRÁFICO 1). 
Tabela 1- Relação de Aplicativos por região e suas notificações.

\begin{tabular}{l|lccccc} 
Usuário & Região & $\begin{array}{c}\text { Notificação } \\
\text { Mordedura } \\
\text { Aplicativo }\end{array}$ & $\begin{array}{c}\text { Notificação } \\
\text { Mordedura } \\
\text { SMS }\end{array}$ & $\begin{array}{c}\text { Ações de } \\
\text { controle }\end{array}$ & $\begin{array}{c}\text { Notificação } \\
\text { Suspeita } \\
\text { Aplicativo }\end{array}$ & $\begin{array}{c}\text { Notificação } \\
\text { Suspeita SMS }\end{array}$ \\
\hline Usuário 02 & M. Batatais & 15 & 2 & 2 & 0 & 0 \\
Usuário 03 & M. Batatais & 0 & 2 & 0 & 0 & 0 \\
Usuário 04 & M. Batatais & 0 & 1 & 0 & 0 & 0 \\
Usuário 05 & M. Batatais & 0 & 2 & 0 & 0 & 0 \\
Usuário 16 & M. Botucatu & 0 & 0 & 0 & 0 & 0 \\
Usuário 17 & M. Botucatu & 0 & 3 & 0 & 0 & 0 \\
Usuário 18 & M. Botucatu & 0 & 0 & 0 & 0 & 0 \\
Usuário 19 & M. Botucatu & 0 & 1 & 0 & 0 & 0 \\
Veterinário 01 & M. Batatais & 0 & 0 & 0 & 0 & 0
\end{tabular}

Fonte: (RABAQUIM, 2017)

Gráfico 1- Incidencia de notificação por mês.

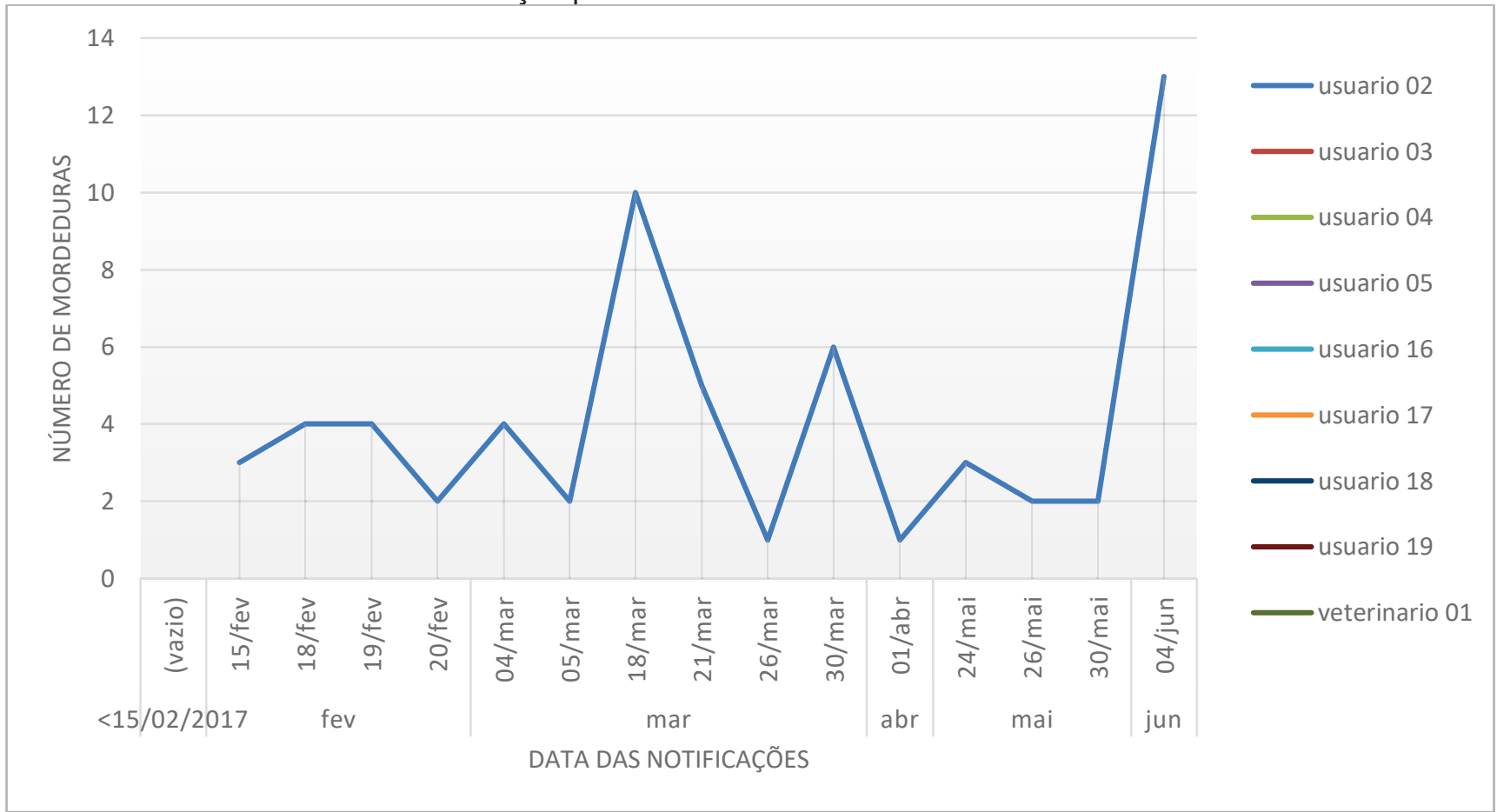

Fonte: (RABAQUIM, 2017) 
Mapa 1- Propriedades Selecionadas.

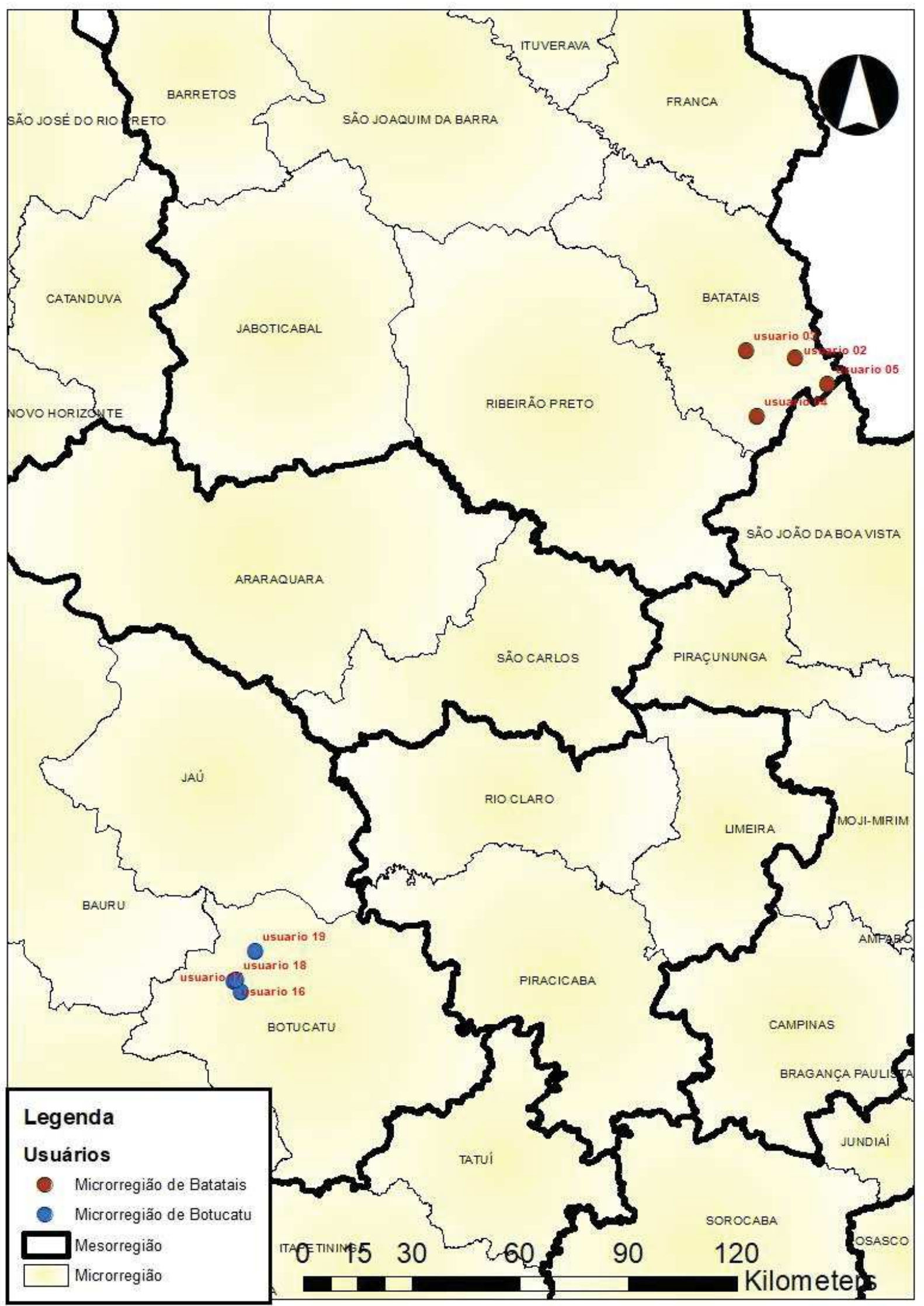

Fonte: (RABAQUIM, 2017) 
Fluxograma 2- Estrutura do Aplicativo de Notificação de Suspeitas e Casos de Raiva

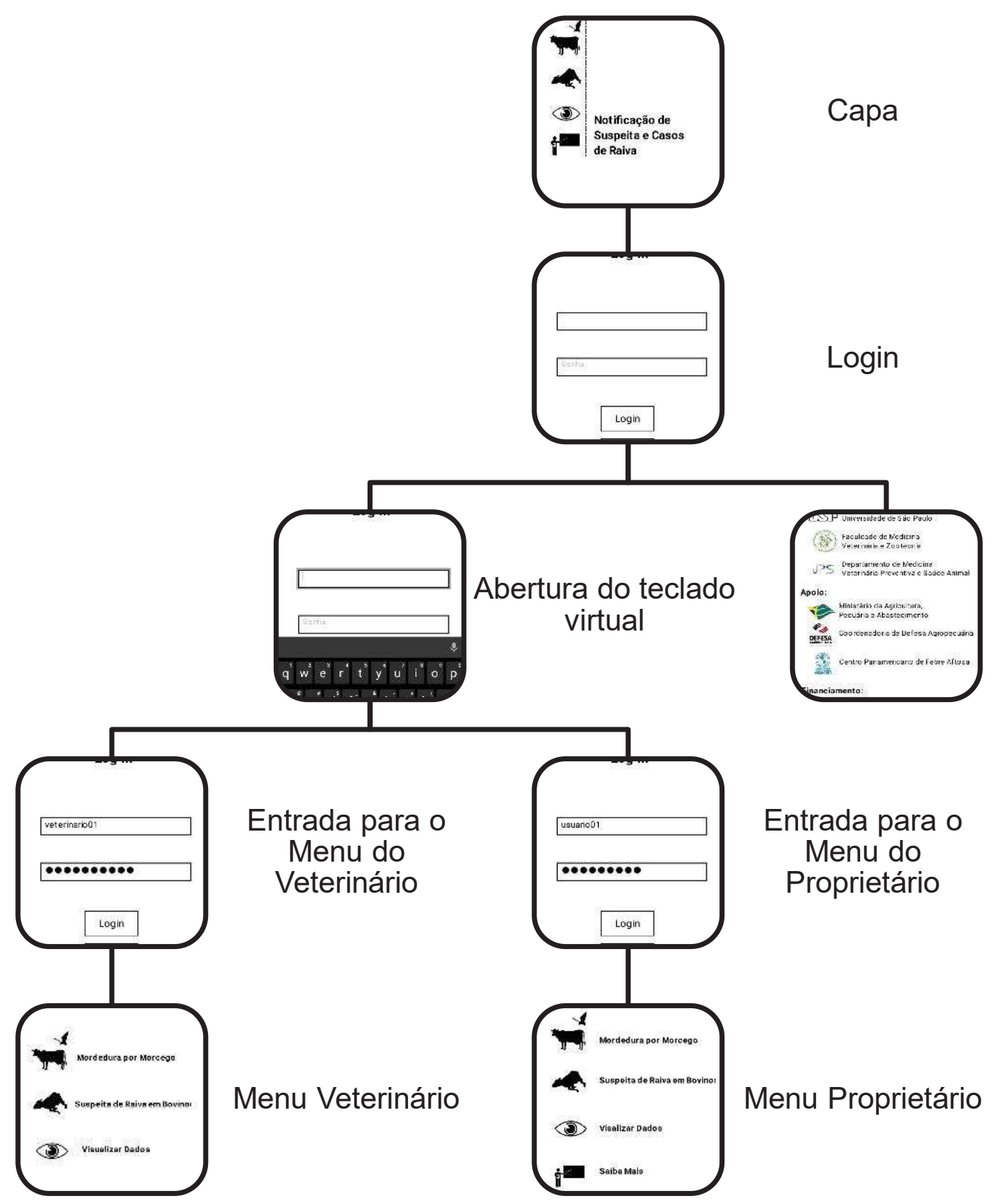

Creditos

Fonte: (RABAQUIM, 2017). 
Fluxograma 3- Menu do Proprietário.

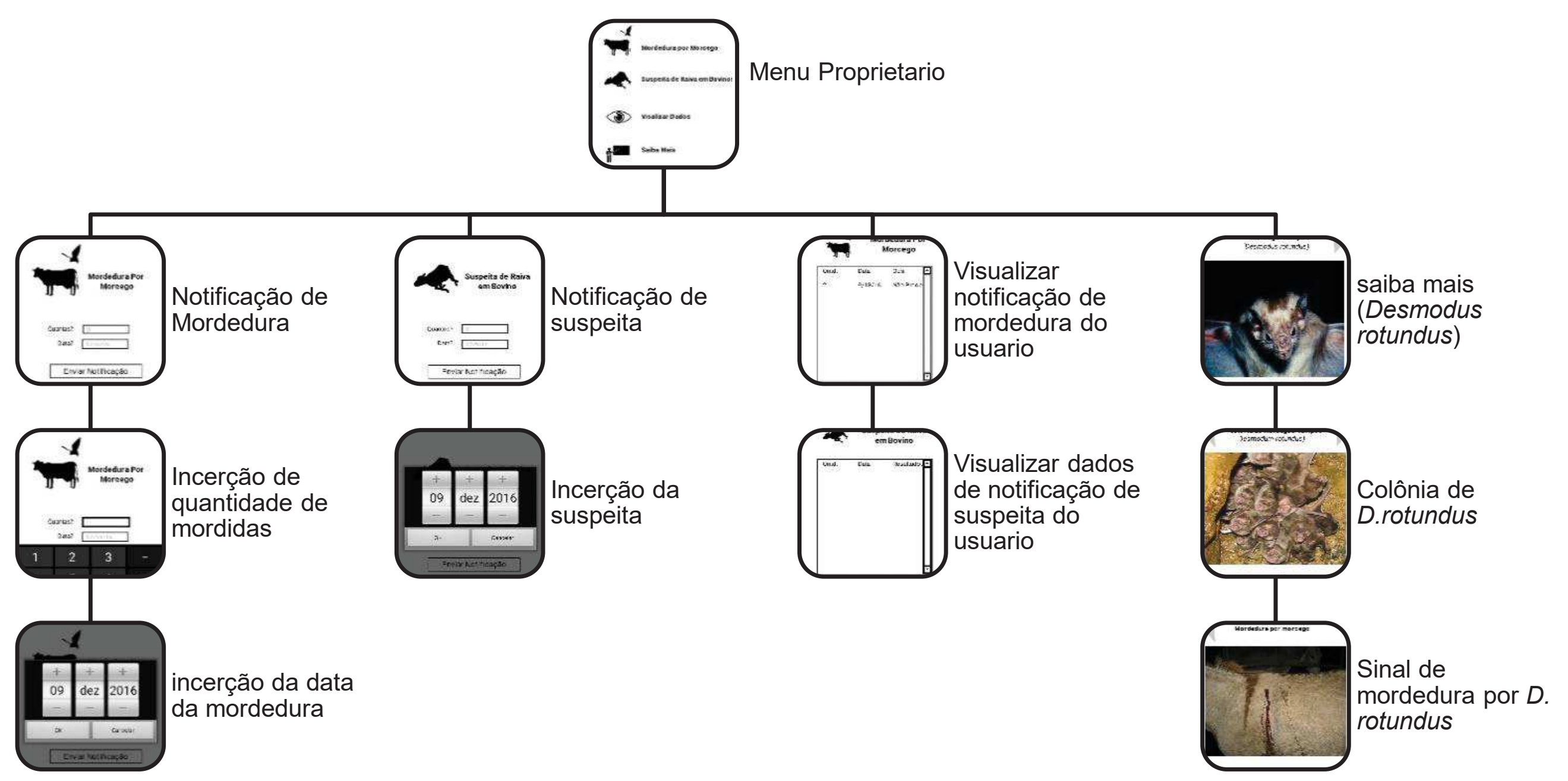


Fluxograma 4- Menu do Veterinário.

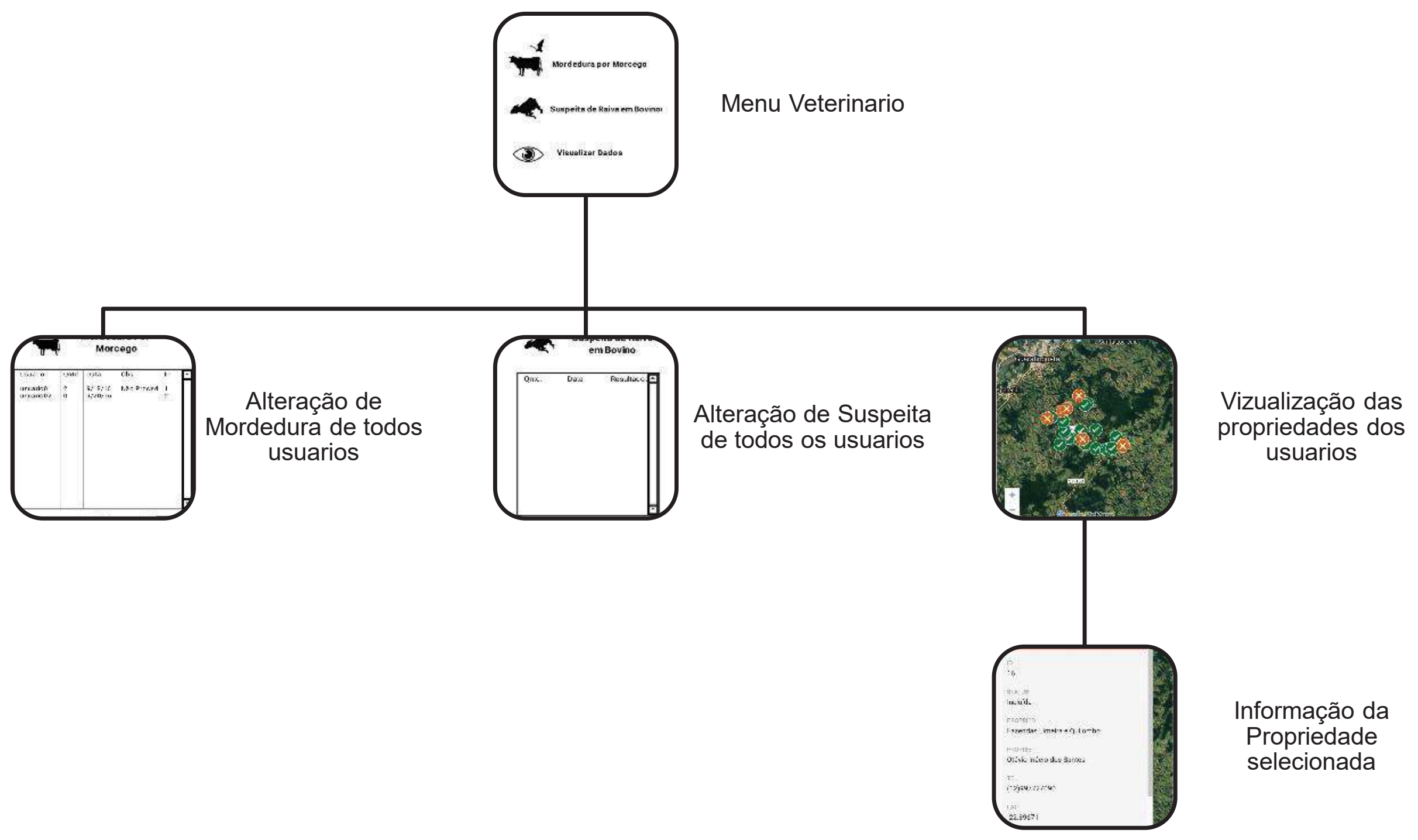




\section{DISCUSSÃO}

O aplicativo móvel foi capaz de armazenar e exibir os dados de notificação de herbívoros de interesse econômico espoliados por morcego hematófago.

$O$ aplicativo foi desenvolvido com base na linguagem de programação de banco de dados SqL, diferenciando-se do aplicativo descrito por Pascoe e colaboradores. (2012).

O desempenho e a responsividade do aplicativo mostraram-se favorável durante o desenvolvimento, podendo ser executado em dispositivos Android ${ }^{\circledR}$ superiores a versão 4.0.3.

O Android ${ }^{\circledR}$ possui uma classe própria para desenvolvimento de layout das telas, que limitou o desenvolvimento do aplicativo. Apesar da utilização do LiveCode ${ }^{\circledR}$, o qual possui um sistema de portabilidade com o Android $^{\circledR}$. Todas as funções e layouts projetados em desktop tiveram que ser readequadas para o dispositivo móvel devido algumas incompatibilidades.

Este aplicativo teve, como vantagem o desenvolvimento em linguagem SqL, que otimizou a comunicação entre aplicativo e banco de dados no servidor, diferenciandose dos aplicativos relacionados na literatura.

$\mathrm{Na}$ literatura analisada, somente Robertson e colaboradores (2010) desenvolveram um aplicativo para dispositivo móvel voltado para a Medicina Veterinária. Esta ferramenta é útil no controle de doenças de impacto econômico, ambiental e na saúde pública. Diferenciando-se um pouco do método utilizado por Robertson e colaboradores (2010) o presente aplicativo contava como vantagem a facilidade de distribuição a proprietários, otimizando o sistema de notificação e economizando recursos financeiros de possíveis setores públicos para a implantação do projeto.

O aplicativo dispunha de duas interfaces diferentes uma para o proprietário e outra para o veterinário responsável pela região o que possibilitava ao médico veterinário fornecer uma resposta ao proprietário quando houvesse necessidade de procedimento laboratorial. Deste modo, este aplicativo otimizaria o sistema de notificação no caso de mordedura por morcego hematófago ou no caso de animais com suspeita de raiva. 
Por outro lado, há desvantagens a serem corrigidas, principalmente no quesito de segurança e na forma de acesso ao banco de dados. Nos artigos analisados, encontramos aplicativos que se comunicam com o servidor e/ou banco de dados através de SMS em modo offline (RANDRIANASOLO et al., 2010; ASANGANSI; BRAA, 2009; PASCOE, et al., 2012; CÁCERES, et al., 2016; ROBERTSON et al., 2010), enquanto este aplicativo ainda depende da conexão com à Internet, o que representa uma desvantagem, pois na região de Guaratingueta não havia acesso à Internet móvel ou fixa, inviabilizando o uso do aplicativo como forma de notificação. Outro ponto a ser ressaltado neste aplicativo é a impossibilidade do usuário criar sua própria senha de acesso, sendo obrigatório o uso de login e senha pré-estabelecidos.

Corroborando com os achados de Asangansi e Braa (2009) o presente estudo deparou-se com dificuldades em encontrar proprietários com acesso a smartphones e conhecimento mínimo de tecnologia para utilizar o aplicativo. No entanto, os moradores demonstraram interesse e aceitabilidade quanto à instalação do aplicativo e a importância da notificação de mordedura.

Como observado por Robertson e colaboradores (2010), que apoio político é importante, a receptividade por parte dos proprietários se mostrou melhor com a presença da equipe de controle da raiva.

Adequando a metodologia utilizada por Asangansi e Braa (2009) e por Robertson e colaboradores (2010) todos os proprietários que tinham acesso à tecnologia foram treinados para utilizar o sistema corretamente.

Nos casos em que os proprietários apresentavam dificuldades ou desconhecimento no uso da ferramenta, optou-se por treinar e instalar os aplicativos em dispositivos móveis de parentes ou funcionários dos proprietários que tivessem com interesse no uso do aplicativo.

Entretanto não houve adesão ao uso do aplicativo como fonte de notificação, a maioria dos proprietários notificaram através de mensagem corroborando com o sistema de notificação criado por Pascoe e colaboradores (2012).

Porém entre todos os aplicativos investigados na pesquisa bibliográfica, nenhum dos sistemas foi desenvolvido para ser utilizado pelos proprietários e nem tiveram objetivo de notificar zoonoses e doenças infecciosas que acometem animais de produção. Poucos trabalhos como o de Robertson e companheiros. (2010) citam a importância da otimização no sistema de notificação em Medicina Veterinária. 
É possível afirmar diante do cenário tecnológico atual e com a ausência de tecnologia para notificação de agravos, o aplicativo desenvolvido vai de encontro à proposta de inserção de tecnologia em ambiente rural e com grande potencial de aplicação em campo. Pelo fato de não haver aplicativos desenvolvidos para o uso do proprietário em ambiente rural, a avaliação comparativa ficou comprometida.

Por fim, diante do resultado obtido com um dos usuários do aplicativo que notificou de maneira adequada e obteve assim uma resposta rápida do Coordenadoria de Defesa Agropecuária, onde foi feito o controle de abrigos de morcegos hematófagos reduzindo assim a incidência de animais espoliados. É possível afirmar que o aplicativo tem potencial para crescer ainda mais em termos de funcionalidade $e$ abrangência.

Com o baixo número de notificações através do aplicativo não foi possível avaliar a aceitabilidade e adesão destes proprietários a nova tecnologia para notificação da ocorrência de mordedura e suspeita de raiva animal. 


\section{CONSIDERAÇÕES}

O aplicativo desenvolvido atendeu aos objetivos propostos de coletar dados de notificação e otimizar o sistema de notificação.

O layout proposto mostrou-se simples e de fácil utilização. Os dados coletados pelo aplicativo e salvos em servidor podem ser facilmente utilizados para análises.

As principais limitações do aplicativo foram:

- Necessitar obrigatoriamente de Internet.

- Não permítir que o proprietário crie seu próprio login e senha.

- Não possuir um sistema de lembrete semanal para os proprietários.

- Não ter um sistema de informação que avise o veterinário de que houve notificação de algum proprietário da sua região.

Para contornar as limitações atuais seria interessante incluir neste aplicativo o uso do serviço SMS para conexão com o banco de dados. A inclusão de um sistema de lembrete semanal para o proprietário notificar; um sistema que permita ao proprietário criar seu login e senha que interaja com a base de cadastros de proprietários do CDA.

Quanto à adesão dos proprietários seria necessário um estudo comportamental da população rural, para assim, conseguir adequar o aplicativo as necessidades desta população. 


\section{REFERÊNCIAS}

ABLESON, W. F. et al. Android Em Ação. Rio de Janeiro: Elsevier, 2012.

ANDROID. Android Interfaces and Architecture. Disponível em:

<https://source.Android.com/devices/index.html>. Acesso em: 27 dez. 2016.

Android ${ }^{\circledR}$ Interfaces and Architecture

ANDROID DEVELOPER.. Android, the world's most popular mobile platform. Disponível em: <https://developer.android.com/about/android.html>. Acesso em: 09 dez. 2016.

ASANGANSI; I.; BRAA. K.. The Emergence of Mobile-Supported National Health Information Systems in Developing Countries. Studies In Health Technology And Informatics, [s.I.], v. 160, n. 2010, p.540-544, 2010. IOS Press.

http://dx.doi.org/10.3233/978-1-60750-588-4-540.

ASSOCIAÇÃO BRASILEIRA DE MARKETING RURAL \& AGRONEGÓCIO (ABMR\&A). Perfil Comportamental e Hábitos de Mídia do Produtor Rural Brasileiro 2013/2014. 6a Onda de Pesquisa. 2014.

BOTUCATU. PREFEITURA DO MUNICÍPIO DE BOTUCATU. . História. Disponível em: <http://www.botucatu.sp.gov.br/>. Acesso em: 28 ago. 2017.

BRASIL. MINISTÉRIO DA SAÚDE. Secretaria de Vigilância em Saúde. Departamento de

Vigilância Epidemiológica. Guia de Bolso de Doenças Infecciosas e Parasitarias

- Brasília: Editora do Ministério da Saúde, 6ª edição, 2006.

BRASIL. INSTITUTO BRASILEIRO DE GEOGRAFIA E ESTATÍSTICA. . Estimativas populacionais para os municípios e para as Unidades da Federação brasileiros em 01.07.2016. 2016. Disponível em:

<http://www.ibge.gov.br/home/estatistica/populacao/estimativa2016/estimativa_dou.s htm>. Acesso em: 28 ago. 2017.

BRASIL. AGÊNCIA NACIONAL DE TELECOMUNICAÇÕES.. . Mobile

Anatel. Disponível em: <http://gatewaysiec.anatel.gov.br/mobileanatel/>. Acesso em: 28 jul. 2017. 
BRASIL. INSTITUTO BRASILEIRO DE GEOGRAFIA E ESTATÍSTICA. . Divisão Regional do Brasil. 2017. Disponível em:

<http://www.ibge.gov.br/home/geociencias/geografia/default_div_int.shtm?c=1>. Acesso em: 28 ago. 2017b.

BRASIL. MINISTÉRIO DA SAÚDE. . Vigilância Participativa. 2017. Disponível em: $<$ http://portalsaude.saude.gov.br/index.php/o-ministerio/principal/leia-mais-oministerio/1315-secretaria-svs/cievs-centro-de-informacoes-estrategicas-e-respostaem-vigilancia-em-saude/l2-cievs/25107-vigilancia-participativa>. Acesso em: 29 nov. 2017c.

CÁCERES, V.M.; CARDOSO, P.; SIDIBE, S.; LAMBERT,S.; LOPEZ, A.; PEDALINO,B.; HERRERA GUIBERT, D.J.. Daily zero-reporting for suspect Ebola using short message service (SMS) in Guinea-Bissau. Public Health, [s.I.], v. 138, p.69-73, set. 2016. Elsevier BV. http://dx.doi.org/10.1016/j.puhe.2016.03.006

CAJURU. PREFEITURA MUNICIPAL DE CAJURU. . O Município. Disponível em: <http://www.cajuru.sp.gov.br/municipio.php>. Acesso em: 28 ago. 2017.

CÁSSIA DOS COQUEIROS. PREFEITURA MUNICIPAL CÁSSIA DOS COQUEIROS. . Histórico: SUA HISTÓRIA. Disponível em:

<http://www.cassiadoscoqueiros.sp.gov.br/site/historico/>. Acesso em: 28 ago. 2017.

COLOMBIA. ORGANIZACIÓN PANAMERICANA DE LA SALUD. . Vigilancia Epidemiológica Basada en la Comunidad...: Una acción clave en la respuesta a las situaciones de emergencias y desastres. 2012. Disponível em:

<http://www.paho.org/col/index.php?option=com_content\&view=article\&id=1753:vigil ancia-epidemiologica-basada-en-comunidad-una-accion-clave-en-la-respuesta-asituaciones-de-emergencias-y-desastres\&Itemid=361>. Acesso em: 29 nov. 2017.

DORODA, R. F.. As Novas Tecnologias e o Espaço Público da Cidade

Contemporânea. 2012. 122 f. Dissertação (Mestrado) - Curso de Arquitetura, Planejamento Urbano Regional, Universidade Regional do Rio Grande do Sul, Porto Alegre, 2012. Disponível em:

<http://www.ufrgs.br/propur/teses_dissertacoes/Raquel_daroda.pdf>. Acesso em: 09 dez. 2016.

FARIA, A. O.. ARTIGOS:Como instalar o Android SDK. Disponível em: $<$ https://pt.opensuse.org/ARTIGOS:Como_instalar_o_Android ${ }^{\circledR}$ _SDK>. Acesso em: 27 dez. 2016.

GARCIA, M.H.O.; JÚNIOR, F.J.P.; BARBOSA, J.R.; SOUSA, G.S.;4 SILVA, A.J.M.; BELTRÃO, L.A.A.. Copa do Mundo FIFA Brasil 2014: vigilância ativa e perfil dos atendimentos de saúde na cidade-sede de Fortaleza, Ceará*. Epidemiologia e Serviços de Saúde, Brasilia, v. 25, n. 3, p.499-510, set. 2016. Instituto Evandro Chagas. http://dx.doi.org/10.5123/s1679-49742016000300006. 
GARGENTA, M.. Learning Android. United States: O’Reilly Media, 2011. 248p.

GREENHALL, A.M.; JOERMAMM, G.; SCHMIDT, U.; SEIDEL, M.R..1983.

Desmodus rotundus Mammalian Species. 202. 6p,

GRESSULI (Brasil). Suinocultura Industrial. Suínos na palma da mão. 2016.

Disponível em: <http://www.suinoculturaindustrial.com.br/imprensa/suinos-na-palmada-mao/20051122-172505-1302>. Acesso em: 09 dez. 2016.

GUARATINGUETA. PREFEITURA DO MUNICÍPIO DA ESTÂNCIA TURÍSTICA DE GUARATINGUETÁ. . A CIDADE. Disponível em: <http://guaratingueta.sp.gov.br/acidade/>. Acesso em: 28 ago. 2017.

INSTITUTO BRASILEIRO DE GEOGRAFIA E ESTATÍSTICA (IBGE). Acesso à Internet e à Televisão e Posse de Telefone Móvel Celular para Uso Pessoal. Pesquisa Nacional por Amostra de Domicílios, 2013. Ministério do Planejamento, Brasil.

LIVE CODE. A development tool designed for speed. Disponível em:

<https://livecode.com/>. Acesso em: 09 dez. 2016.

MARKET SHARE STATISTICS FOR INTERNET TECHNOLOGIES (NETMARKETSHARE) (Org.). Mobile/Tablet Top Operating System Share Trend. 2016. Disponível em: <https://www.netmarketshare.com/operating-systemmarket-

share. aspx?qprid=9\&qpcustomb=1\&qpct=4\&qpcustomd=br\&qpsp=191\&qpnp=25\&qp timeframe=M>. Acesso em: 09 dez. 2016.

MEDNIEKS, Z.;DORMIN, L.; MEIKE, G.B.; NAKAMURA,M.. Programming android: Java Programmin for the new Generation of Mobile Divices. 2.ed. United States:

O'Reilly. 2012. 566p.

MINISTERIO DA AGRICULTURA, PECUARIA E ABASTECIMENTO (MAPA). Controle de Raiva em Herbívoros: Manual Técnico, Brasília. 2005.

OUM, S.; CHANDRAMOHAN, D.; CAIRNCROSS, S.. Community-based surveillance: a pilot study from rural Cambodia. Tropical Medicine And International Health, London, v. 10, n. 7, p.689-697, jul. 2005.

PASCOE, L.; LUNGO, J. H.; KAASBØLL, J. J. \& KOLELENI, I. (2012). Collecting Integrated Disease Surveillance and Response Data through Mobile Phones, In Paul Cunningham \& Miriam Cunningham (ed.), IST-Africa 2012 
Conference Proceedings. International Information Management Corporation Limited. ISBN 978-1-905824-34-2. Research paper. s 1-6

PEDALINO,B.; HERRERA GUIBERT, D.J.. Daily zero-reporting for suspect Ebola using short message service (SMS) in Guinea-Bissau. Public Health, [s.I.], v. 138, p.69-73, set. 2016. Elsevier BV. http://dx.doi.org/10.1016/j.puhe.2016.03.006.

RANDRIANASOLO, L.; RAOELINA, Y.; RATSITORAHINA, M; RAVOLOMANANA, L.; ANDRIAMANDIMBY, S.; HERAUD, J.M.; RAKOTOMANANA, F.; RAMANJATO, R.; RANDRIANARIVO-SOLOFONIAINA, A.E.; RICHARD, V.. Sentinel surveillance system for early outbreak detection in Madagascar. Bmc Public

Health, Madagascar, v. 31, n. 10, p.1-8, 21 jan. 2010. Disponível em:

<https://bmcpublichealth.biomedcentral.com/articles/10.1186/1471-2458-10-31>. Acesso em: 24 jul. 2017.

REIS, N.R.; PERACCHI, A.L.; PEDRO, W.A.; LIMA, I.P. (eds.), 2007. Morcegos do Brasil. Londrina: Reis NR.

ROBERTSON, C.; SAWFORD, K.; DANIEL, S.L.A.; NELSON, T.A.; STEPHEN, C.. Mobile Phone-based Infectious Disease Surveillance System, Sri Lanka. Emerging Infectious Diseases, Atlanta, v. 16, n. 10, p.1524-1531, out. 2010. Disponível em: <https://wwwnc.cdc.gov/eid/article/16/10/10-0249_article>. Acesso em: 24 jul. 2017.

STAIR, R.M.; REYNOLDS, G. W.. PRINCÍPIOS DE SISTEMAS DE INFORMAÇÃO. 11. ed. São Paulo: Cengage, 2016. 752 p.

UIEDA, W. Morcegos hematófagos e a raiva dos herbívoros no Brasil. In:

SEMINÁRIO CIÊNCIAS FIUBE (1.: 1987: Uberaba). Anais. Uberaba,1987.p.13-29.

World Organisation for Animal Health (OIE); 'Listed diseases, infections and infestations in force in 2017'. Disponível em: < http://www.oie.int/animal-health-in-theworld/oie-listed-diseases-2017/>. Acesso em: 28 jul. 2017.; 


\section{APÊNDICE 1}

Fluxograma 5- Diagrama de Caso e Uso

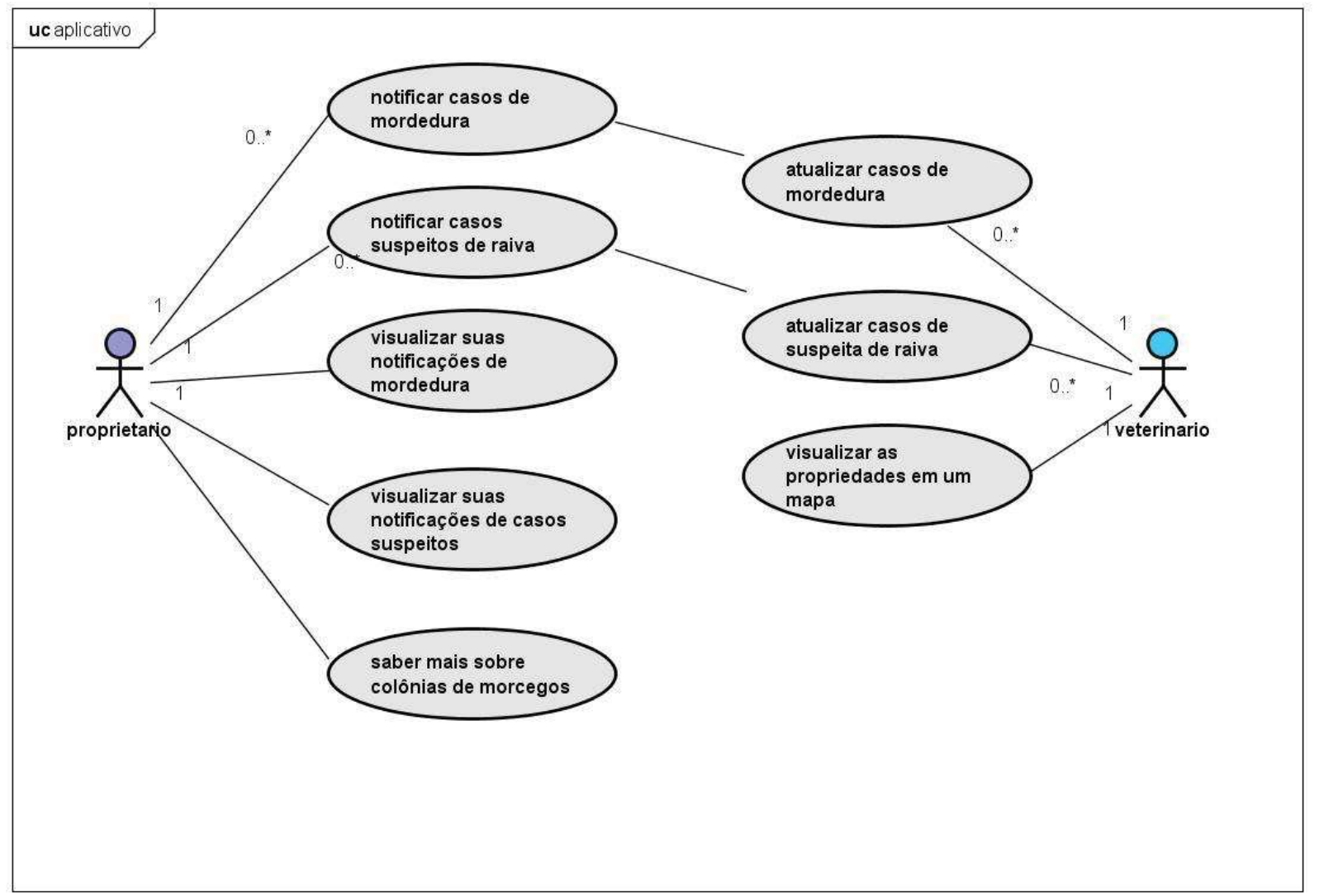

Fonte: (RABAQUIM, 2017) 
Fluxograma 6- Organograma de Notificação de Mordedura por Morcego Hematófago

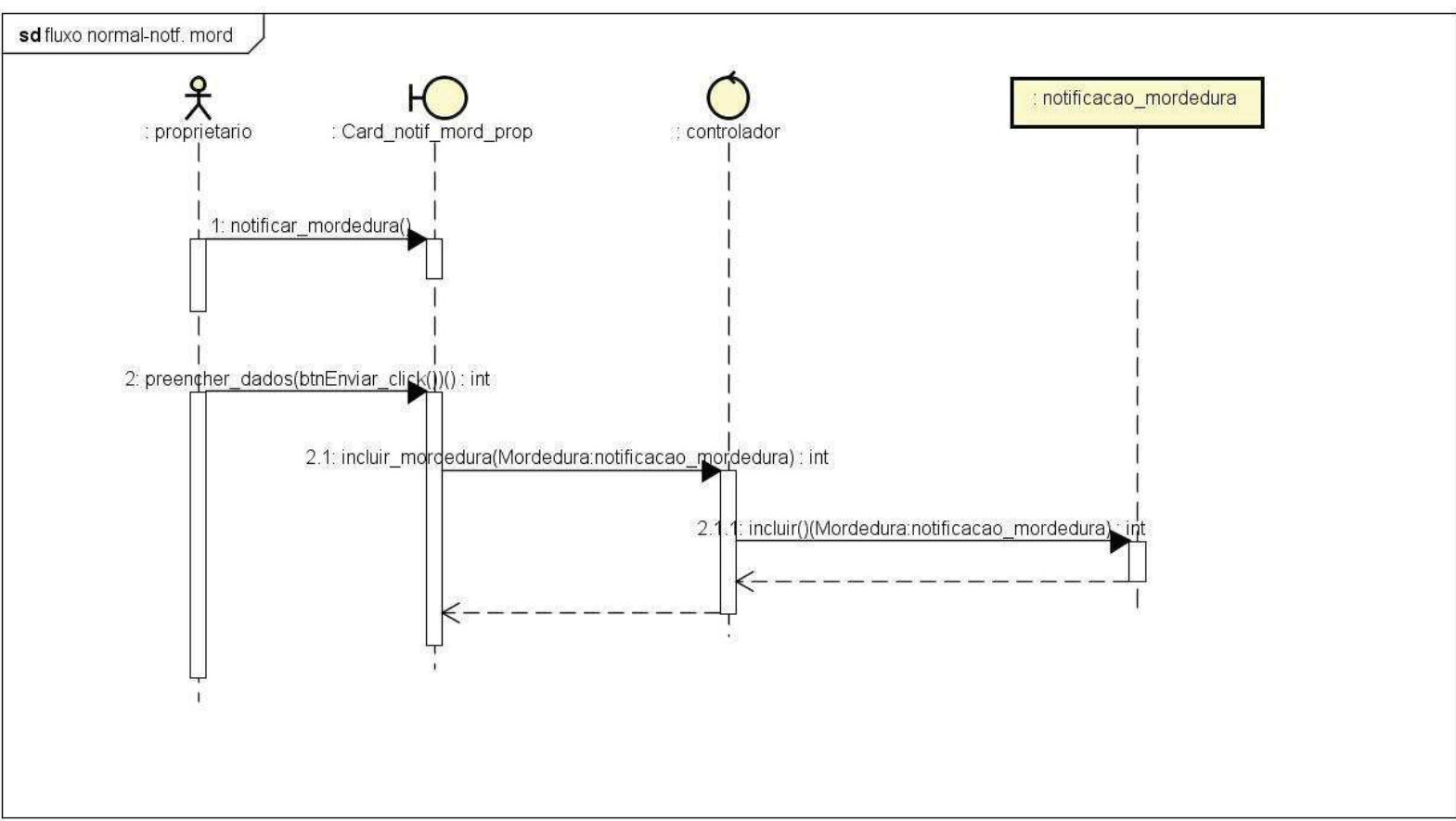

Fluxograma 7- Or

Fonte: (RABAQUIM, 2017)

al

sd fluxo normal-notf.susp.

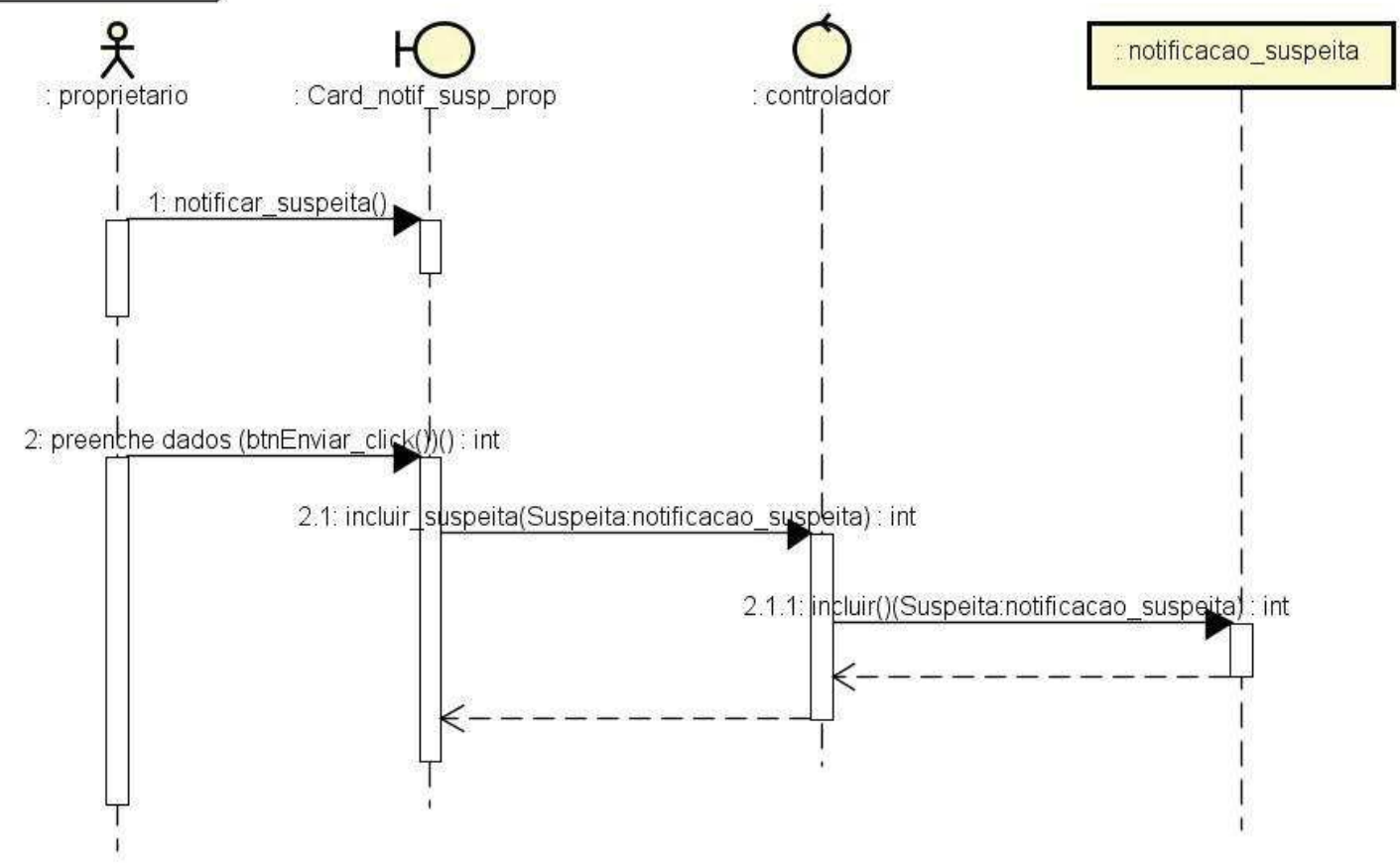

Fonte: (RABAQUIM, 2017) 
Fluxograma 8- Organograma de Visualização das Notificações de Mordedura por Morcego Hematófagos

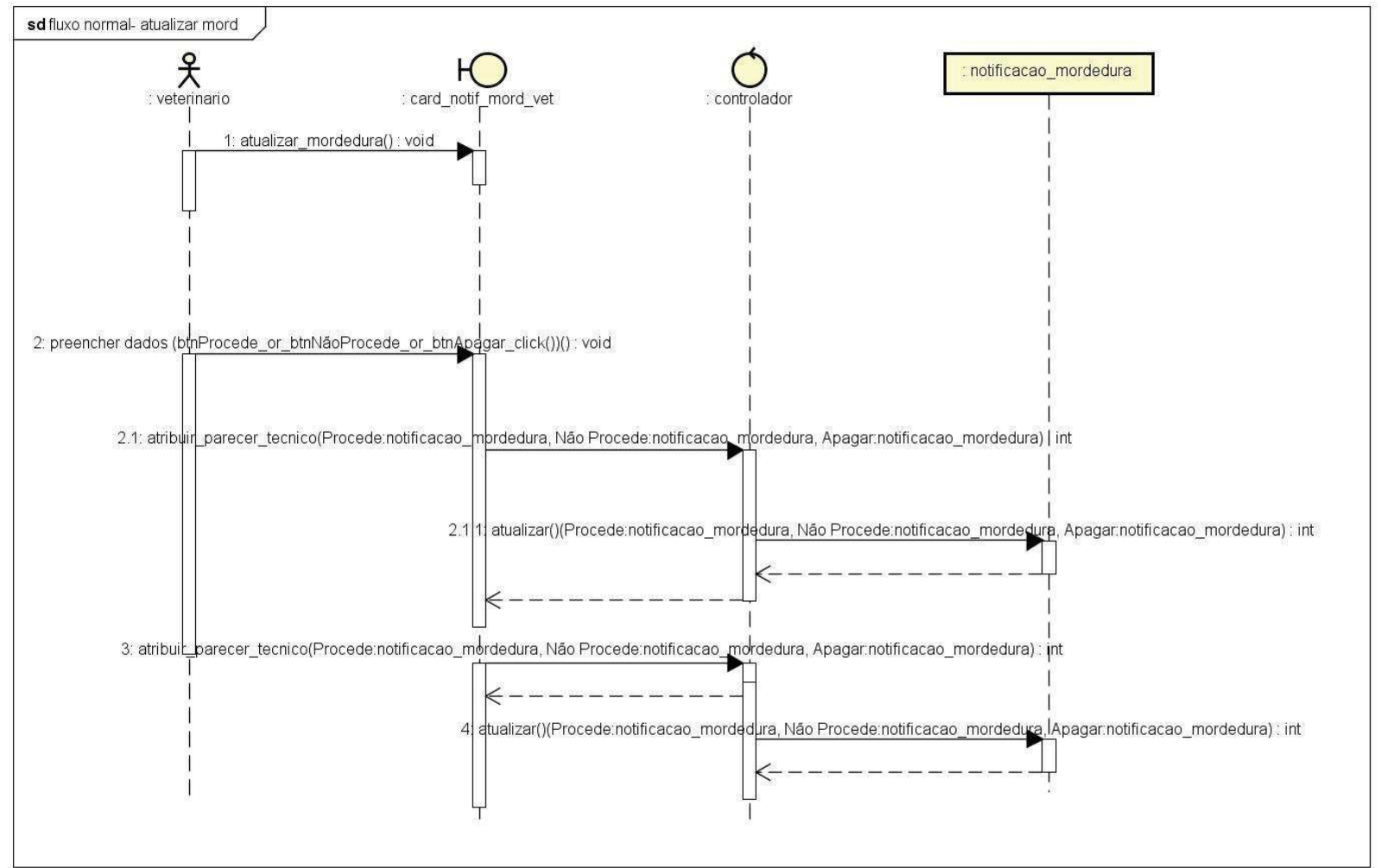

Fonte: (RABAQUIM, 2017)

powered by Astahn

Fluxograma 9- Organograma de Visualização das Notificações de Casos Suspeitos de Raiva Animal

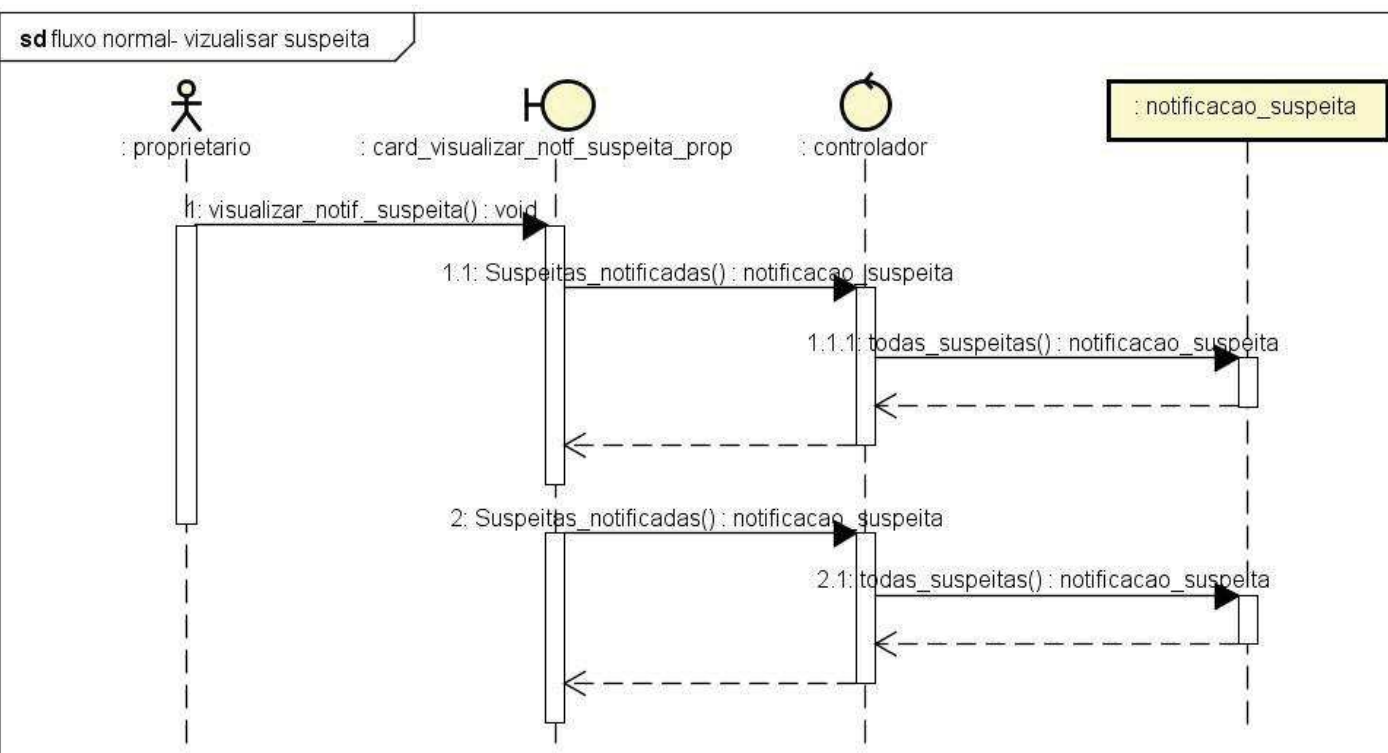


Fluxograma 10- Organograma de Atualização das Notificações de Mordedura por Morcego Hematófago

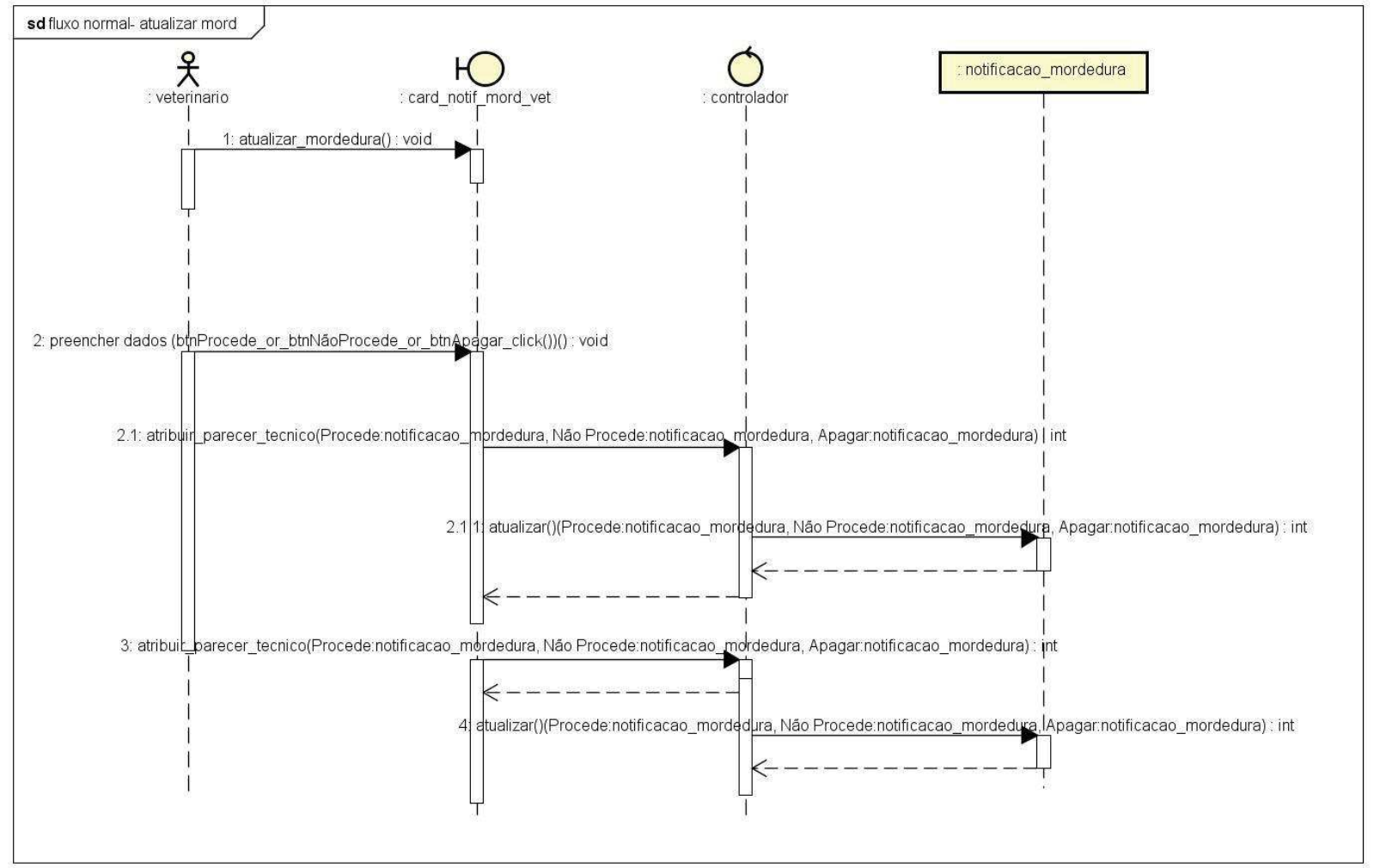

Fonte: (RABAQUIM, 2017)

powered by Astahn

Fluxograma 11- Organograma de Atualização das Notificações de Caso Suspeito de Raiva Animal.

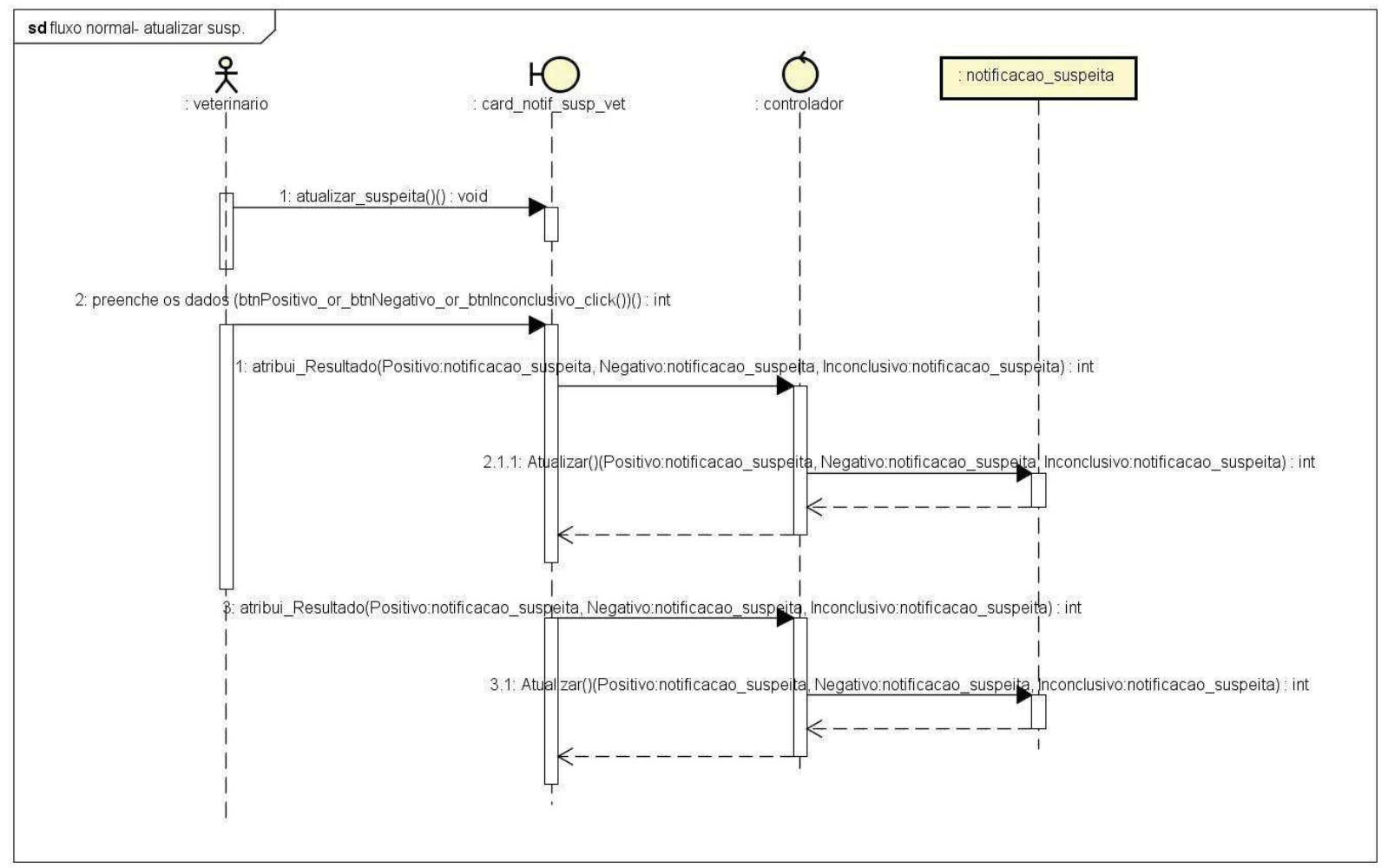

Fonte: (RABAQUIM, 2017) 


\section{APÊNDICE 2}

\section{Manual de Instalação do aplicativo de notificação de mordedura de morcego}

$1^{\circ}$ faça o download (baixe) do aplicativo que está no e-mail para o celular

$2^{\circ}$ vá em configurações - segurança - e ative a fonte desconhecida

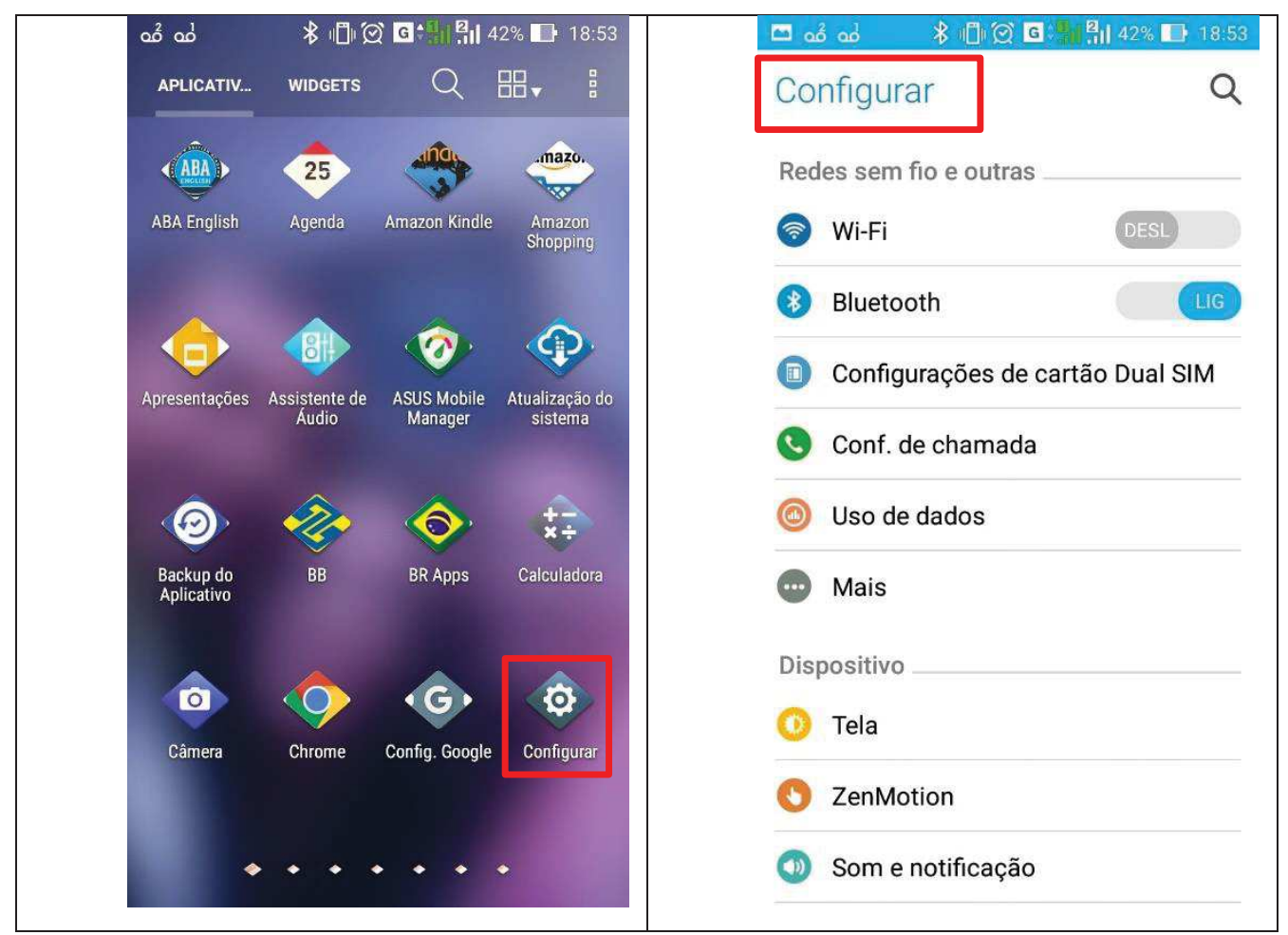




\begin{tabular}{|c|c|}
\hline 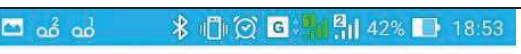 & 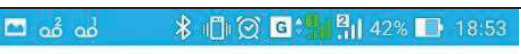 \\
\hline Configurar & $\leftarrow$ Segurança \\
\hline (9) Localização & Criptografia \\
\hline (1) Modo Fácil & Criptografar dispositivo \\
\hline () Modo crianças & Bloqueio do cartão SIM \\
\hline (5) Bloqueio de tela & Configurar bloqueio do SIM \\
\hline (1) Segurança & Senhas \\
\hline (2) Contas & Tornar as senhas visíveis \\
\hline A. Idioma e entrada & Administração do dispositivo \\
\hline (9) Fazer backup e redefinir & $\begin{array}{l}\text { Administradores do dispositivo } \\
\text { Visualizar ou desativar administradores do }\end{array}$ \\
\hline (2) Captura de tela & dispositivo \\
\hline Sistema & $\begin{array}{l}\text { Fontes desconhecidas } \\
\text { Permitir a instalação de apps de } \\
\text { fontes desconhecidas }\end{array}$ \\
\hline (C) Data e hora & Armazanamantn da rrodenriaic \\
\hline
\end{tabular}

\section{$3^{\circ}$ vá nos arquivos baixados e clique no aplicativo para instalar}

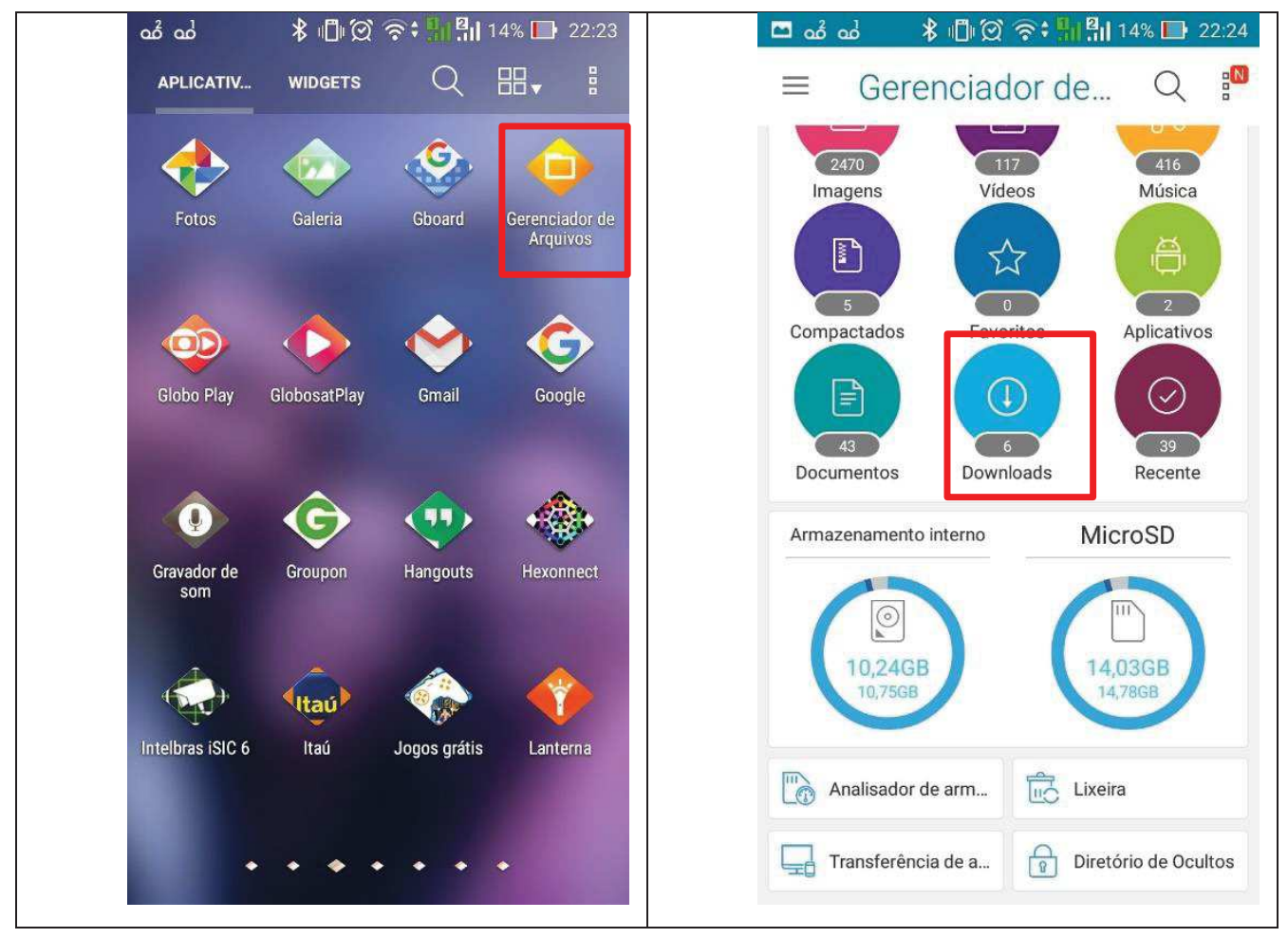




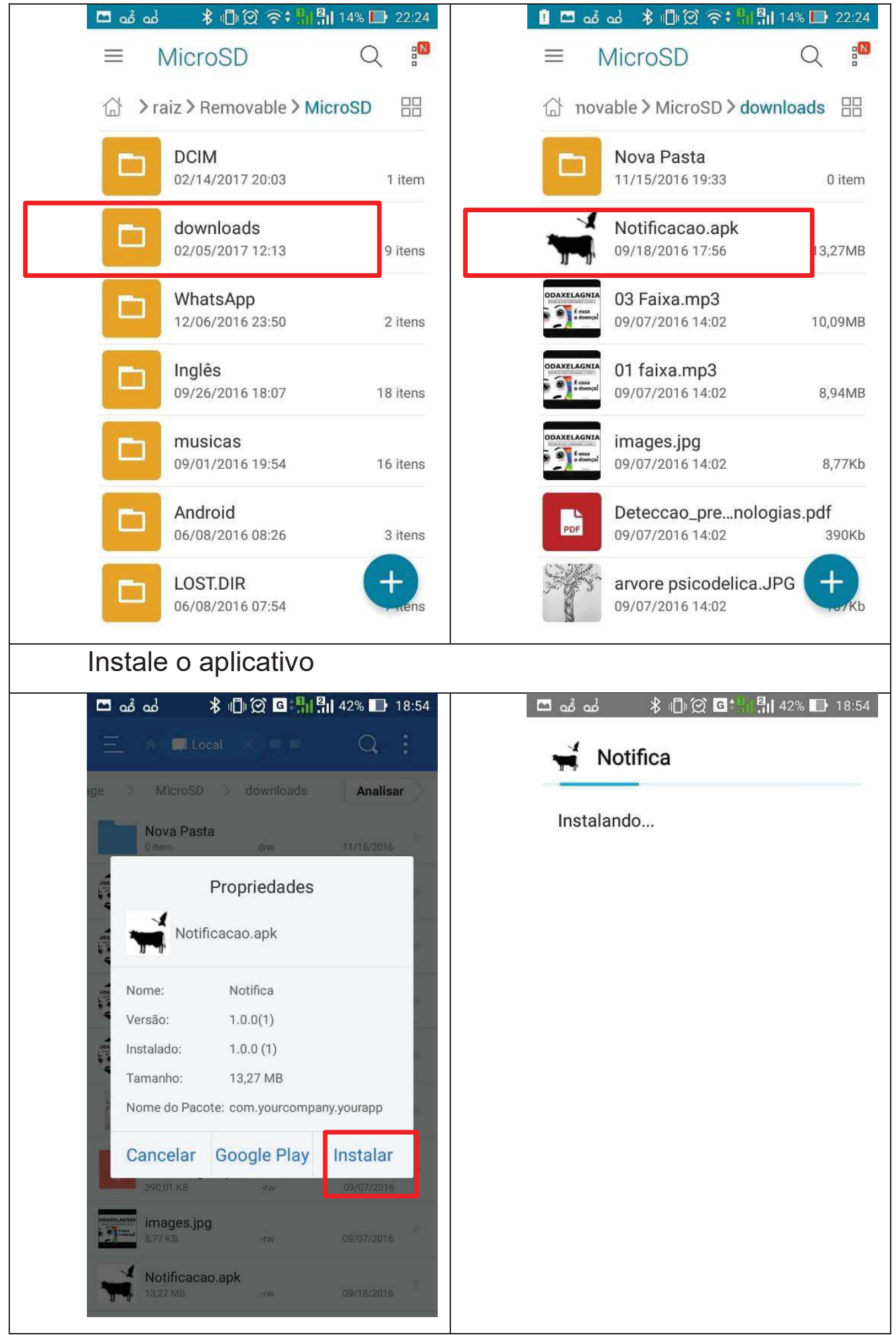




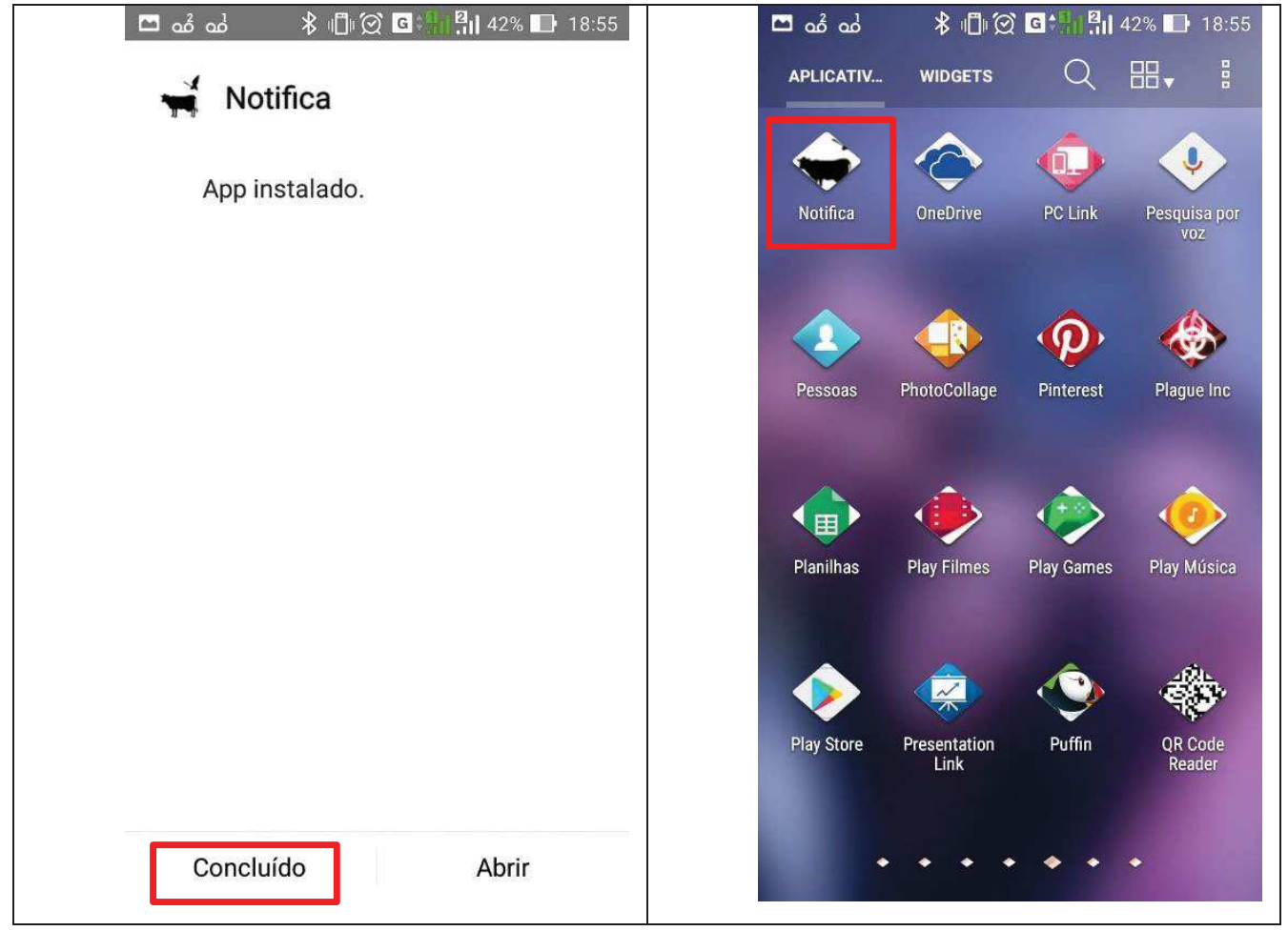

Parabéns seu aplicativo de notificação esta instalado. 


\section{APÊNDICE 3}

Quadro 1- Comamdos do aplicativo.

\begin{tabular}{|c|c|c|}
\hline \multicolumn{2}{|l|}{ TELA } & COMANDO \\
\hline \multicolumn{2}{|l|}{ TELA 1} & $\begin{array}{l}\text { on openStack } \\
\text { wait } 3 \text { seconds } \\
\text { go to tela "login" } \\
\text { end openStack }\end{array}$ \\
\hline \multicolumn{2}{|l|}{ TELA 2} & $\begin{array}{l}\text { on openTela } \\
\text { set the fullscreenmode of this stack to "exactFit" } \\
\text { set the foregroundColor of field "usuario" to "gray" } \\
\text { set the foregroundColor of field "senha" to "gray" } \\
\text { put "Usuário" into field "usuario" } \\
\text { put "Senha" into field "senha" } \\
\text { focus on field "usuario" } \\
\text { end openTela }\end{array}$ \\
\hline & $\begin{array}{l}\text { CAIXA DE } \\
\text { TEXTO } 1\end{array}$ & $\begin{array}{l}\text { on openField } \\
\text { put empty into me } \\
\text { set the foregroundColor of field "usuario" to "black" } \\
\text { end openField }\end{array}$ \\
\hline & $\begin{array}{l}\text { CAIXA DE } \\
\text { TEXTO } 2\end{array}$ & $\begin{array}{l}\text { on openField } \\
\text { put empty into me } \\
\text { set the foregroundColor of field "senha" to "black" } \\
\text { end openField } \\
\text { on textChanged } \\
\text { local tImageld } \\
\text { put } 17582 \text { into tImageld } \\
\text { repeat with } x=1 \text { to the number of chars of me } \\
\text { set the imageSource of char } x \text { of me to tlmageld } \\
\text { end repeat } \\
\text { end textChanged }\end{array}$ \\
\hline & BOTÃO 1 & 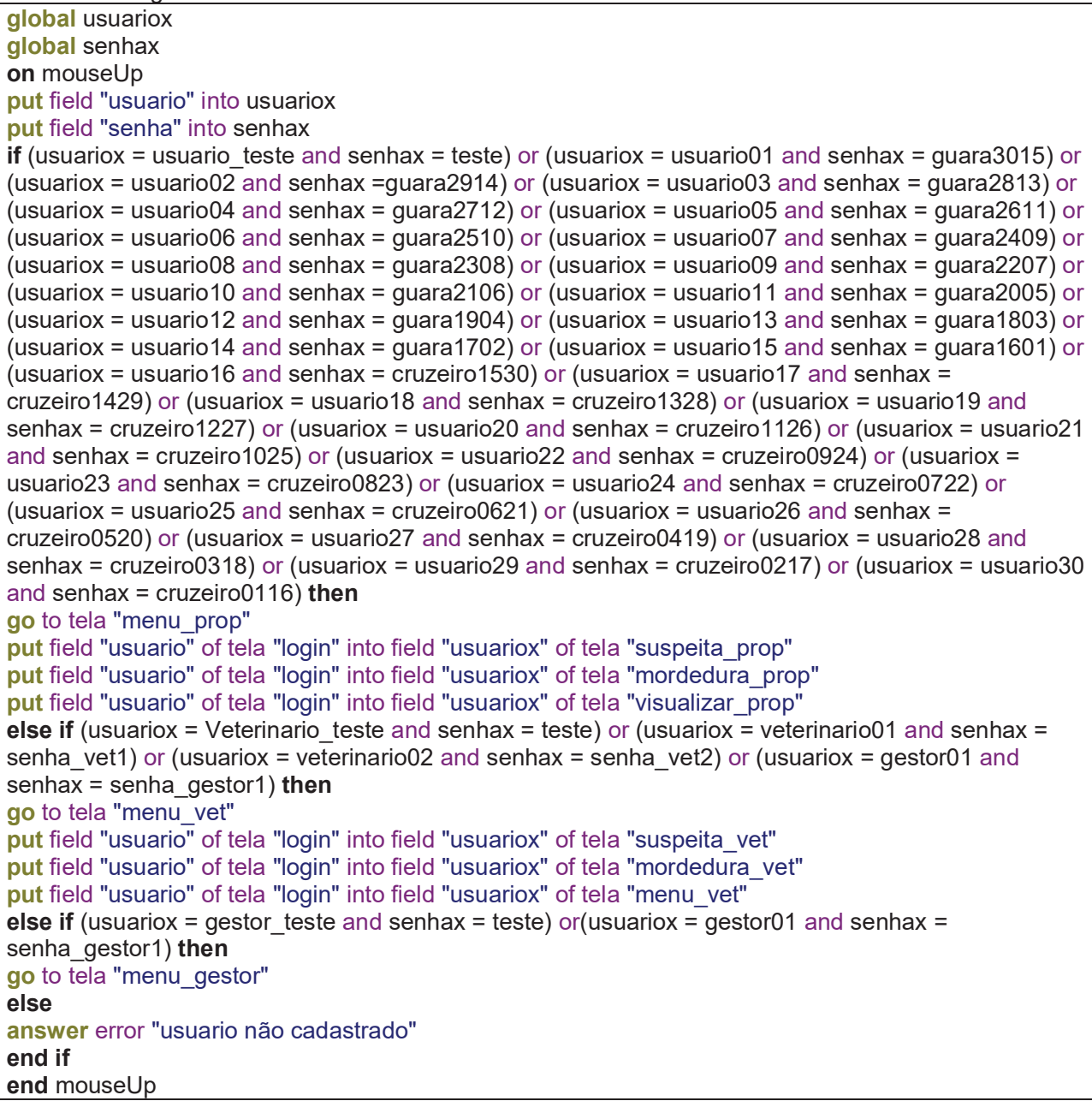 \\
\hline & BOTÃO 2 & $\begin{array}{l}\text { on mouseup } \\
\text { go to tela "creditos" }\end{array}$ \\
\hline
\end{tabular}




\begin{tabular}{|c|c|c|}
\hline & end mouseup \\
\hline \multicolumn{2}{|l|}{ TELA 3} & $\begin{array}{l}\text { on mouseUp } \\
\text { go to tela "login" } \\
\text { end mouseUp }\end{array}$ \\
\hline \multicolumn{2}{|l|}{ TELA 4} & $\begin{array}{l}\text { on opentela } \\
\text { set the fullscreenmode of this stack to "exactFit" } \\
\text { end opentela }\end{array}$ \\
\hline & BOTÃO 1 & $\begin{array}{l}\text { on mouseup } \\
\text { go to tela "mordedura_prop" } \\
\text { end mouseup }\end{array}$ \\
\hline & BOTÃO 2 & $\begin{array}{l}\text { on mouseup } \\
\text { go to tela "suspeita_prop" } \\
\text { end mouseup }\end{array}$ \\
\hline & BOTÃO 3 & $\begin{array}{l}\text { on mouseUp } \\
\text { go to tela "visualizar_prop" } \\
\text { end mouseUp }\end{array}$ \\
\hline & BOTÃO 4 & $\begin{array}{l}\text { on mouseUp } \\
\text { go to tela "Saiba_mais" } \\
\text { end mouseUp }\end{array}$ \\
\hline \multicolumn{2}{|l|}{ TELA 5} & $\begin{array}{l}\text { on openTela } \\
\text { put } 0 \text { into field "Mordedura" } \\
\text { put system date into field "Datamordedura" } \\
\text { set the foregroundColor of field "Mordedura" to "gray" } \\
\text { set the foregroundColor of field "Datamordedura" to "gray" } \\
\text { end openTela }\end{array}$ \\
\hline & $\begin{array}{l}\text { CAIXA DE } \\
\text { TEXTO } 1\end{array}$ & $\begin{array}{l}\text { on openField } \\
\text { put empty into me } \\
\text { set the foregroundColor of field "Mordedura" to "black" } \\
\text { mobileSetKeyboardType "number" } \\
\text { end openField }\end{array}$ \\
\hline & $\begin{array}{l}\text { CAIXA DE } \\
\text { TEXTO } 2\end{array}$ & $\begin{array}{l}\text { on openField } \\
\text { put empty into me } \\
\text { set the foregroundColor of field "Datamordedura" to "black" } \\
\text { mobilePickDate "date" } \\
\text { put the result into me } \\
\text { if field "Datamordedura" is "cancel" then } \\
\text { put empty into me } \\
\text { end if } \\
\text { end openField }\end{array}$ \\
\hline & BOTÃO 1 & $\begin{array}{l}\text { on mouseUp } \\
\text { put "200.XXX.XXX.XXX:XXXX " into dbhost } \\
\text { put "notificacao" into dbname } \\
\text { put "usuario" into dbuser } \\
\text { put "senha" into dbpwd } \\
\text { put revOpenDatabase ("MySQL",dbhost, dbname, dbuser, dbpwd) into conn } \\
\text { if field "Mordedura" is empty or field "Datamordedura" is empty then } \\
\text { answer "Digite o número de mordeduras E a data antes de enviar a notificação" } \\
\text { else } \\
\text { if conn is a number then } \\
\text { put conn into ConlD } \\
\text { put "Conexion ID:" \& conn into field "CID" } \\
\text { put field "Mordedura" into mordedura } \\
\text { put field "Datamordedura" into datamordedura } \\
\text { put field "usuariox" into usuario } \\
\text { put "insert into mordedura ( mordedura, datamordedura, usuario) values } \\
\text { ("\&mordedura\&","\&datamordedura\&"', '"\&usuario\&"')" into tSQL } \\
\text { revExecuteSQL ConID, tSQL } \\
\text { Answer info "Obrigado pela colaboração!" } \\
\text { put null into field "Mordedura" } \\
\text { put null into field "Datamordedura" } \\
\text { go to tela "menu_prop" } \\
\text { else } \\
\text { put empty into ConID } \\
\text { put empty into field "CID" } \\
\text { answer error " Ocorreu um erro ao conectar-se com o banco de dados" \&cr\&conn } \\
\text { end if } \\
\text { end if } \\
\text { end mouseUp }\end{array}$ \\
\hline \multicolumn{2}{|l|}{ TELA 6} & $\begin{array}{l}\text { on openTela } \\
\text { put } 1 \text { into field "Suspeita" } \\
\text { put system date into field "Datasuspeita" } \\
\text { set the foregroundColor of field "Suspeita" to "gray" } \\
\text { set the foregroundColor of field "Datasuspeita" to "gray" } \\
\text { end openTela }\end{array}$ \\
\hline
\end{tabular}




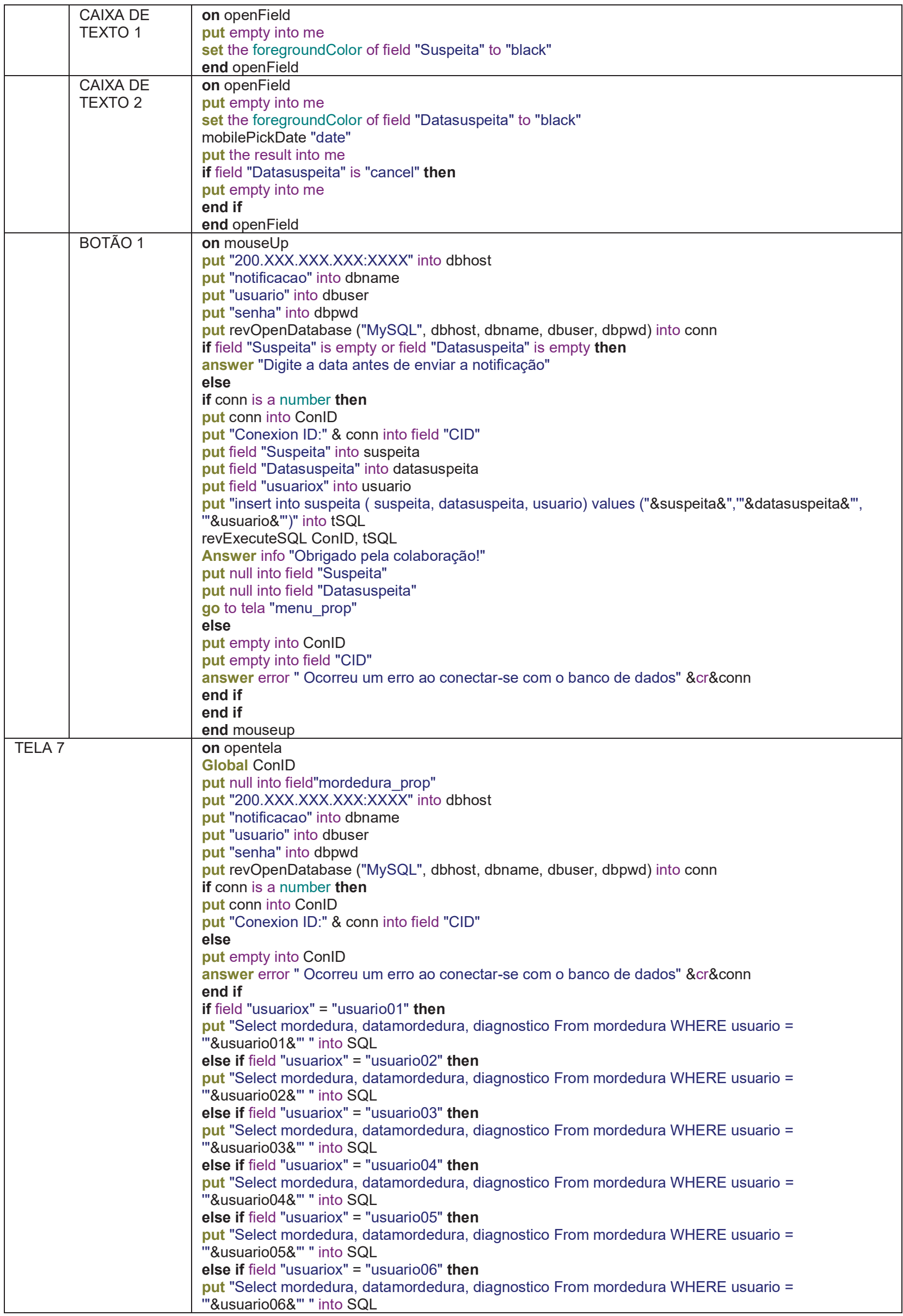


else if field "usuariox" = "usuario07" then

put "Select mordedura, datamordedura, diagnostico From mordedura WHERE usuario = "'\&usuario07\&"' " into SQL

else if field "usuariox" = "usuario08" then

put "Select mordedura, datamordedura, diagnostico From mordedura WHERE usuario =

'"\&usuario08\&"' " into SQL

else if field "usuariox" = "usuario09" then

put "Select mordedura, datamordedura, diagnostico From mordedura WHERE usuario =

"'\&usuario09\&"' " into SQL

else if field "usuariox" = "usuario10" then

put "Select mordedura, datamordedura, diagnostico From mordedura WHERE usuario =

'"\&usuario10\&"' " into SQL

else if field "usuariox" = "usuario11" then

put "Select mordedura, datamordedura, diagnostico From mordedura WHERE usuario = '"\&usuario11\&"' " into SQL

else if field "usuariox" = "usuario12" then

put "Select mordedura, datamordedura, diagnostico From mordedura WHERE usuario = "'\&usuario12\&"' " into SQL

else if field "usuariox" = "usuario13" then

put "Select mordedura, datamordedura, diagnostico From mordedura WHERE usuario =

"'\&usuario13\&"' " into SQL

else if field "usuariox" = "usuario14" then

put "Select mordedura, datamordedura, diagnostico From mordedura WHERE usuario =

"'\&usuario14\&"' " into SQL

else if field "usuariox" = "usuario15" then

put "Select mordedura, datamordedura, diagnostico From mordedura WHERE usuario =

'"\&usuario15\&"' " into SQL

else if field "usuariox" = "usuario16" then

put "Select mordedura, datamordedura, diagnostico From mordedura WHERE usuario =

"'\&usuario16\&"' " into SQL

else if field "usuariox" = "usuario17" then

put "Select mordedura, datamordedura, diagnostico From mordedura WHERE usuario =

'"\&usuario17\&"' " into SQL

else if field "usuariox" = "usuario18" then

put "Select mordedura, datamordedura, diagnostico From mordedura WHERE usuario =

"'\&usuario18\&"' " into SQL

else if field "usuariox" = "usuario19" then

put "Select mordedura, datamordedura, diagnostico From mordedura WHERE usuario =

"'\&usuario19\&"' " into SQL

else if field "usuariox" = "usuario20" then

put "Select mordedura, datamordedura, diagnostico From mordedura WHERE usuario =

'"\&usuario20\&"' " into SQL

else if field "usuariox" = "usuario21" then

put "Select mordedura, datamordedura, diagnostico From mordedura WHERE usuario =

"'\&usuario21\&"' " into SQL

else if field "usuariox" = "usuario22" then

put "Select mordedura, datamordedura, diagnostico From mordedura WHERE usuario =

"'\&usuario22\&"' " into SQL

else if field "usuariox" = "usuario23" then

put "Select mordedura, datamordedura, diagnostico From mordedura WHERE usuario =

"'\&usuario23\&"' " into SQL

else if field "usuariox" = "usuario24" then

put "Select mordedura, datamordedura, diagnostico From mordedura WHERE usuario =

"'\&usuario24\&"' " into SQL

else if field "usuariox" = "usuario25" then

put "Select mordedura, datamordedura, diagnostico From mordedura WHERE usuario =

"'\&usuario25\&"' " into SQL

else if field "usuariox" = "usuario26" then

put "Select mordedura, datamordedura, diagnostico From mordedura WHERE usuario =

"'\&usuario26\&"' " into SQL

else if field "usuariox" = "usuario27" then

put "Select mordedura, datamordedura, diagnostico From mordedura WHERE usuario =

"'\&usuario27\&"' " into SQL

else if field "usuariox" = "usuario28" then

put "Select mordedura, datamordedura, diagnostico From mordedura WHERE usuario =

'"\&usuario28\&"' " into SQL

else if field "usuariox" = "usuario29" then

put "Select mordedura, datamordedura, diagnostico From mordedura WHERE usuario =

'"\&usuario29\&"' " into SQL

else if field "usuariox" = "usuario30" then

put "Select mordedura, datamordedura, diagnostico From mordedura WHERE usuario =

'"\&usuario30\&"' " into SQL

end if

put revDataFromQuery (tab,cr,ConID, SQL) into datos

if item 1 of datos = "revdberr" then

answer error " ocorreu um erro ao finalizar a consulta de dados" \&cr\&datos\&title 


\begin{tabular}{|c|c|}
\hline & $\begin{array}{l}\text { else } \\
\text { put "Qntd."\& tab \&"Data"\& tab\&"Obs." into line } 1 \text { field "mordedura_prop" } \\
\text { put datos into line } 3 \text { field "mordedura_prop" } \\
\text { end if } \\
\text { end opentela }\end{array}$ \\
\hline TELA 8 & 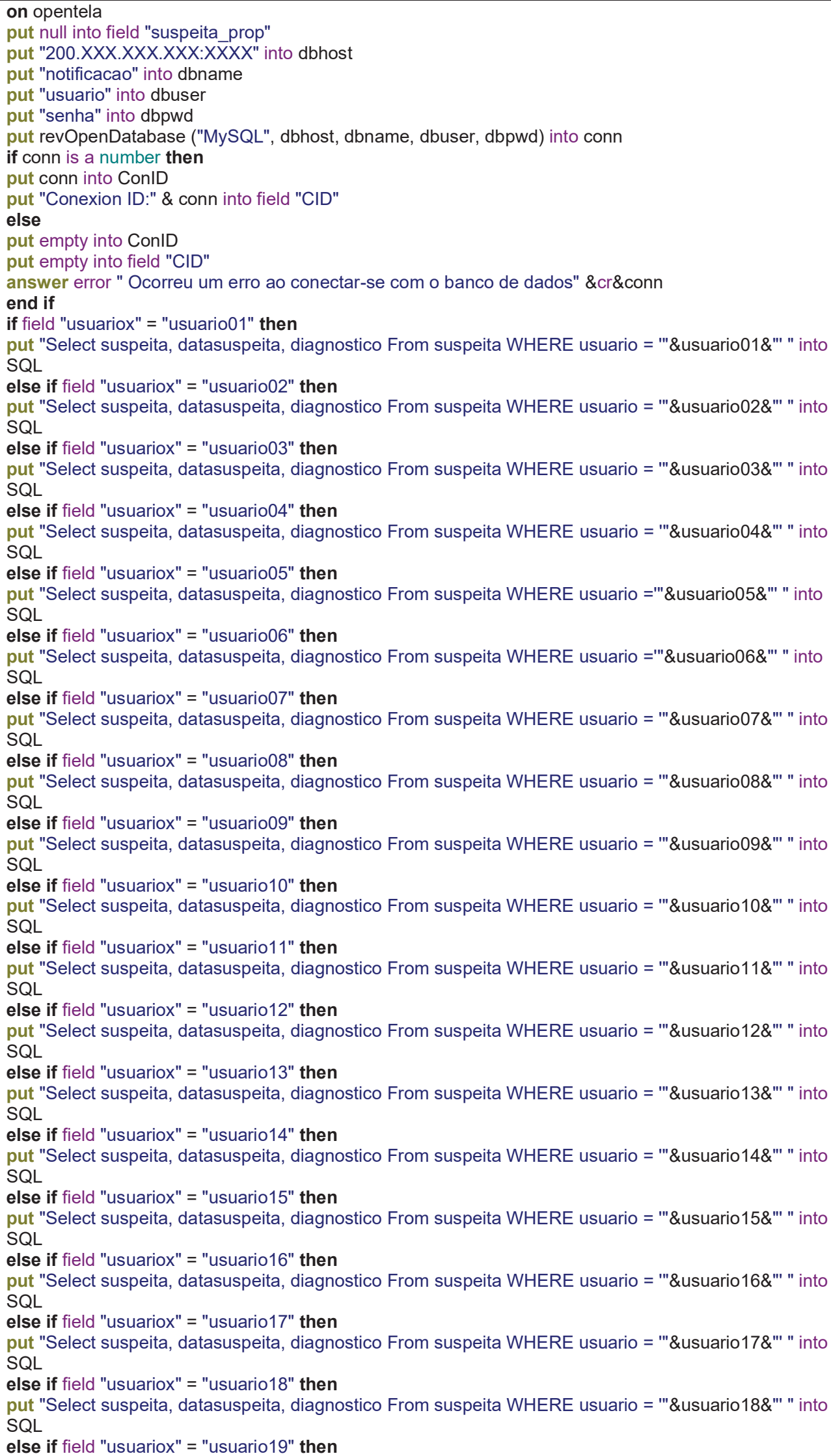 \\
\hline
\end{tabular}




\begin{tabular}{|c|c|c|}
\hline TELA 9 & & $\begin{array}{l}\text { put "Select suspeita, datasuspeita, diagnostico From suspeita WHERE usuario = "'\&usuario19\&"' " into } \\
\text { SQL } \\
\text { else if field "usuariox" = "usuario20" then } \\
\text { put "Select suspeita, datasuspeita, diagnostico From suspeita WHERE usuario = "'\&usuario20\&"' " into } \\
\text { SQL } \\
\text { else if field "usuariox" = "usuario21" then } \\
\text { put "Select suspeita, datasuspeita, diagnostico From suspeita WHERE usuario = "'\&usuario21\&"' " into } \\
\text { SQL } \\
\text { else if field "usuariox" = "usuario22" then } \\
\text { put "Select suspeita, datasuspeita, diagnostico From suspeita WHERE usuario = "'\&usuario22\&"' " into } \\
\text { SQL } \\
\text { else if field "usuariox" = "usuario23" then } \\
\text { put "Select suspeita, datasuspeita, diagnostico From suspeita WHERE usuario = "'\&usuario23\&"' " into } \\
\text { SQL } \\
\text { else if field "usuariox" = "usuario24" then } \\
\text { put "Select suspeita, datasuspeita, diagnostico From suspeita WHERE usuario = '"\&usuario24\&"' " into } \\
\text { SQL } \\
\text { else if field "usuariox" = "usuario25" then } \\
\text { put "Select suspeita, datasuspeita, diagnostico From suspeita WHERE usuario = "'\&usuario25\&"' " into } \\
\text { SQL } \\
\text { else if field "usuariox" = "usuario26" then } \\
\text { put "Select suspeita, datasuspeita, diagnostico From suspeita WHERE usuario = "'\&usuario26\&"' " into } \\
\text { SQL } \\
\text { else if field "usuariox" = "usuario27" then } \\
\text { put "Select suspeita, datasuspeita, diagnostico From suspeita WHERE usuario = "'\&usuario27\&"' " into } \\
\text { SQL } \\
\text { else if field "usuariox" = "usuario28" then } \\
\text { put "Select suspeita, datasuspeita, diagnostico From suspeita WHERE usuario = "'\&usuario28\&"' " into } \\
\text { SQL } \\
\text { else if field "usuariox" = "usuario29" then } \\
\text { put "Select suspeita, datasuspeita, diagnostico From suspeita WHERE usuario = '"\&usuario29\&"' " into } \\
\text { SQL } \\
\text { else if field "usuariox" = "usuario30" then } \\
\text { put "Select suspeita, datasuspeita, diagnostico From suspeita WHERE usuario = '"\&usuario30\&"' " into } \\
\text { SQL } \\
\text { end if } \\
\text { put revDataFromQuery (tab,cr,ConID, SQL) into datos } \\
\text { if item } 1 \text { of datos = "revdberr" then } \\
\text { answer error " ocorreu um erro ao finalizar a consulta de dados" \&cr\&datos\&title } \\
\text { else } \\
\text { put "Qntd."\& tab \&"Data"\& tab\&"Resultados" into line } 1 \text { field "suspeita_prop" } \\
\text { put datos into line } 3 \text { field "suspeita_prop" } \\
\text { end if } \\
\text { end opentela } \\
\text { on mouseUp }\end{array}$ \\
\hline IELA Y & & $\begin{array}{l}\text { go to tela "saiba_mais1" } \\
\text { end mouseUp }\end{array}$ \\
\hline TELA 10 & & $\begin{array}{l}\text { on mouseUp } \\
\text { go to tela "saiba_mais2" } \\
\text { end mouseUp }\end{array}$ \\
\hline TELA 11 & & $\begin{array}{l}\text { on mouseUp } \\
\text { go to tela "saiba_mais2" } \\
\text { end mouseUp }\end{array}$ \\
\hline TELA 12 & & $\begin{array}{l}\text { on opentela } \\
\text { set the fullscreenmode of this stack to "exactFit" } \\
\text { end opentela }\end{array}$ \\
\hline & BOTÃO 1 & $\begin{array}{l}\text { on mouseup } \\
\text { go to tela "mordedura_vet" } \\
\text { end mouseup }\end{array}$ \\
\hline & BOTÃO 2 & $\begin{array}{l}\text { on mouseup } \\
\text { go to tela "suspeita_vet" } \\
\text { end mouseup }\end{array}$ \\
\hline & BOTÃO 3 & $\begin{array}{l}\text { on mouseUp } \\
\text { if field "usuariox" = "veterinario01" then } \\
\text { go to tela "visualizar_vet" } \\
\text { else if field "usuariox" = "veterinario02" then } \\
\text { go to tela "visualizar_vet2" } \\
\text { end if } \\
\text { end mouseUp }\end{array}$ \\
\hline TELA 13 & & $\begin{array}{l}\text { on opentela } \\
\text { Global ConID } \\
\text { put null into field "mordedura_vet" } \\
\text { put null into field "Id_Linha" } \\
\text { put the dbhost of me \& "200.XXX.XXX.XXX:XXXX"\& the dbport of me into dbhost } \\
\text { put "notificacao" into dbname }\end{array}$ \\
\hline
\end{tabular}




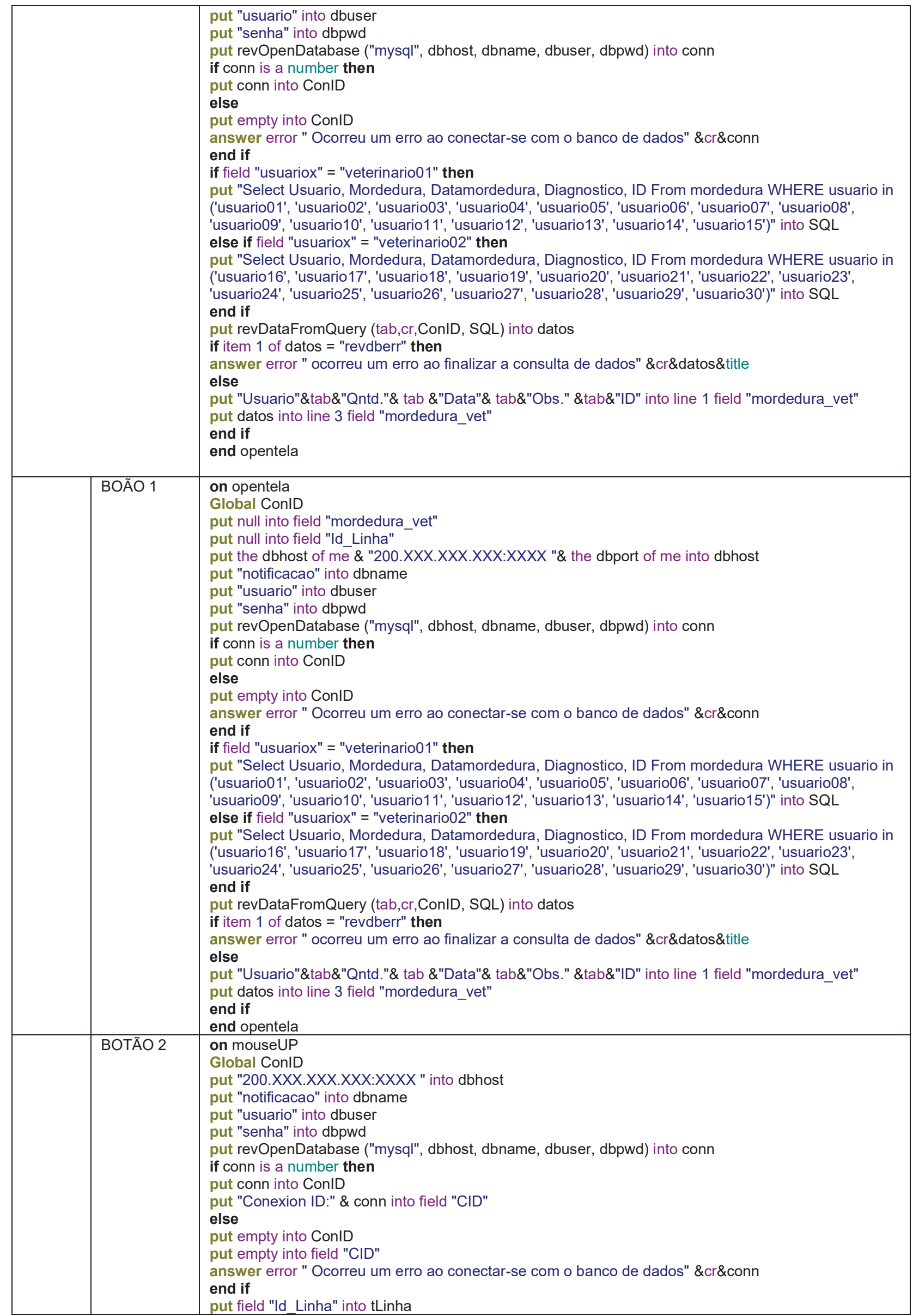




\begin{tabular}{|c|c|c|}
\hline & & $\begin{array}{l}\text { put "UPDATE mordedura SET Diagnostico = 'Não Procede' WHERE ID = "\& tLinha into SQL } \\
\text { Answer info "Você alterou o statos de uma notificação- Não Procede " } \\
\text { revExecuteSQL ConID, tSQL } \\
\text { put revDataFromQuery (tab,cr,ConID, SQL) into datos } \\
\text { put null into field "mordedura_vet" } \\
\text { if field "usuariox" = "veterinario01" then } \\
\text { put "Select usuario, mordedura, datamordedura, diagnostico, ID From mordedura WHERE usuario in } \\
\text { ('usuario01', 'usuario02', 'usuario03', 'usuario04', 'usuario05', 'usuario06', 'usuario07', 'usuario08', } \\
\text { 'usuario09', 'usuario10', 'usuario11', 'usuario12', 'usuario13', 'usuario14', 'usuario15')" into SQL } \\
\text { else if field "usuariox" = "veterinario02" then } \\
\text { put "Select usuario, mordedura, datamordedura, diagnostico, ID From mordedura WHERE usuario in } \\
\text { ('usuario16', 'usuario17', 'usuario18', 'usuario19', 'usuario20', 'usuario21', 'usuario22', 'usuario23', } \\
\text { 'usuario24', 'usuario25', 'usuario26', 'usuario27', 'usuario28', 'usuario29', 'usuario30')" into SQL } \\
\text { end if } \\
\text { put revDataFromQuery (tab,cr,ConID, SQL) into datos } \\
\text { if item } 1 \text { of datos = "revdberr" then } \\
\text { answer error " ocorreu um erro ao finalizar a consulta de dados" \&cr\&datos\&title } \\
\text { else } \\
\text { put "Usuario"\&tab\&"Qntd. "\& tab \&"Data"\& tab\&"Obs."\&tab\&"ID" into line } 1 \text { field "mordedura_vet" } \\
\text { put datos into line } 3 \text { field "mordedura_vet" } \\
\text { put empty into field "Id_Linha" } \\
\text { end if } \\
\text { end mouseUP }\end{array}$ \\
\hline & BOTÃO 3 & $\begin{array}{l}\text { on mouseUP } \\
\text { Global ConID } \\
\text { put "200.XXX.XXX.XXX:XXXX " into dbhost } \\
\text { put "notificacao" into dbname } \\
\text { put "usuario" into dbuser } \\
\text { put "senha" into dbpwd } \\
\text { put revOpenDatabase ("mysql", dbhost, dbname, dbuser, dbpwd) into conn } \\
\text { if conn is a number then } \\
\text { put conn into ConID } \\
\text { put "Conexion ID:" \& conn into field "CID" } \\
\text { else } \\
\text { put empty into ConID } \\
\text { put empty into field "CID" } \\
\text { answer error " Ocorreu um erro ao conectar-se com o banco de dados" \&cr\&conn } \\
\text { end if } \\
\text { put field "Id_Linha" into tLinha } \\
\text { put "UPDATE mordedura SET Diagnostico = ' ' WHERE ID = "\& tLinha into SQL } \\
\text { Answer info "Você apagou o statos de uma notificação" } \\
\text { revExecuteSQL ConID, tSQL } \\
\text { put revDataFromQuery (tab,cr,ConID, SQL) into datos } \\
\text { put null into field "mordedura_vet" } \\
\text { if field "usuariox" = "veterinario01" then } \\
\text { put "Select usuario, mordedura, datamordedura, diagnostico, ID From mordedura WHERE usuario in } \\
\text { ('usuario01', 'usuario02', 'usuario03', 'usuario04', 'usuario05', 'usuario06', 'usuario07', 'usuario08', } \\
\text { 'usuario09', 'usuario10', 'usuario11', 'usuario12', 'usuario13', 'usuario14', 'usuario15')" into SQL } \\
\text { else if field "usuariox" = "veterinario02" then } \\
\text { put "Select usuario, mordedura, datamordedura, diagnostico, ID From mordedura WHERE usuario in } \\
\text { ('usuario16', 'usuario17', 'usuario18', 'usuario19', 'usuario20', 'usuario21', 'usuario22', 'usuario23', } \\
\text { 'usuario24', 'usuario25', 'usuario26', 'usuario27', 'usuario28', 'usuario29', 'usuario30')" into SQL } \\
\text { end if } \\
\text { put revDataFromQuery (tab,cr,ConID, SQL) into datos } \\
\text { if item } 1 \text { of datos = "revdberr" then } \\
\text { answer error " ocorreu um erro ao finalizar a consulta de dados" \&cr\&datos\&title } \\
\text { else } \\
\text { put "Usuario"\&tab\&"Qntd. "\& tab \&"Data"\& tab\&"Obs." \&tab\&"ID" into line 1 field "mordedura_vet" } \\
\text { put datos into line } 3 \text { field "mordedura_vet" } \\
\text { put empty into field "Id_Linha" } \\
\text { end if } \\
\text { end mouseUP }\end{array}$ \\
\hline TELA 14 & & $\begin{array}{l}\text { on opentela } \\
\text { put null into field"suspeita_vet" } \\
\text { put "200.XXX.XXX.XXX:XXXX" into dbhost } \\
\text { put "notificacao" into dbname } \\
\text { put "usuario" into dbuser } \\
\text { put "senha" into dbpwd } \\
\text { put revOpenDatabase ("MySQL", dbhost, dbname, dbuser, dbpwd) into conn } \\
\text { if conn is a number then } \\
\text { put conn into ConID } \\
\text { put "Conexion ID:" \& conn into field "CID" } \\
\text { else } \\
\text { put empty into ConID } \\
\text { put empty into field "CID" }\end{array}$ \\
\hline
\end{tabular}




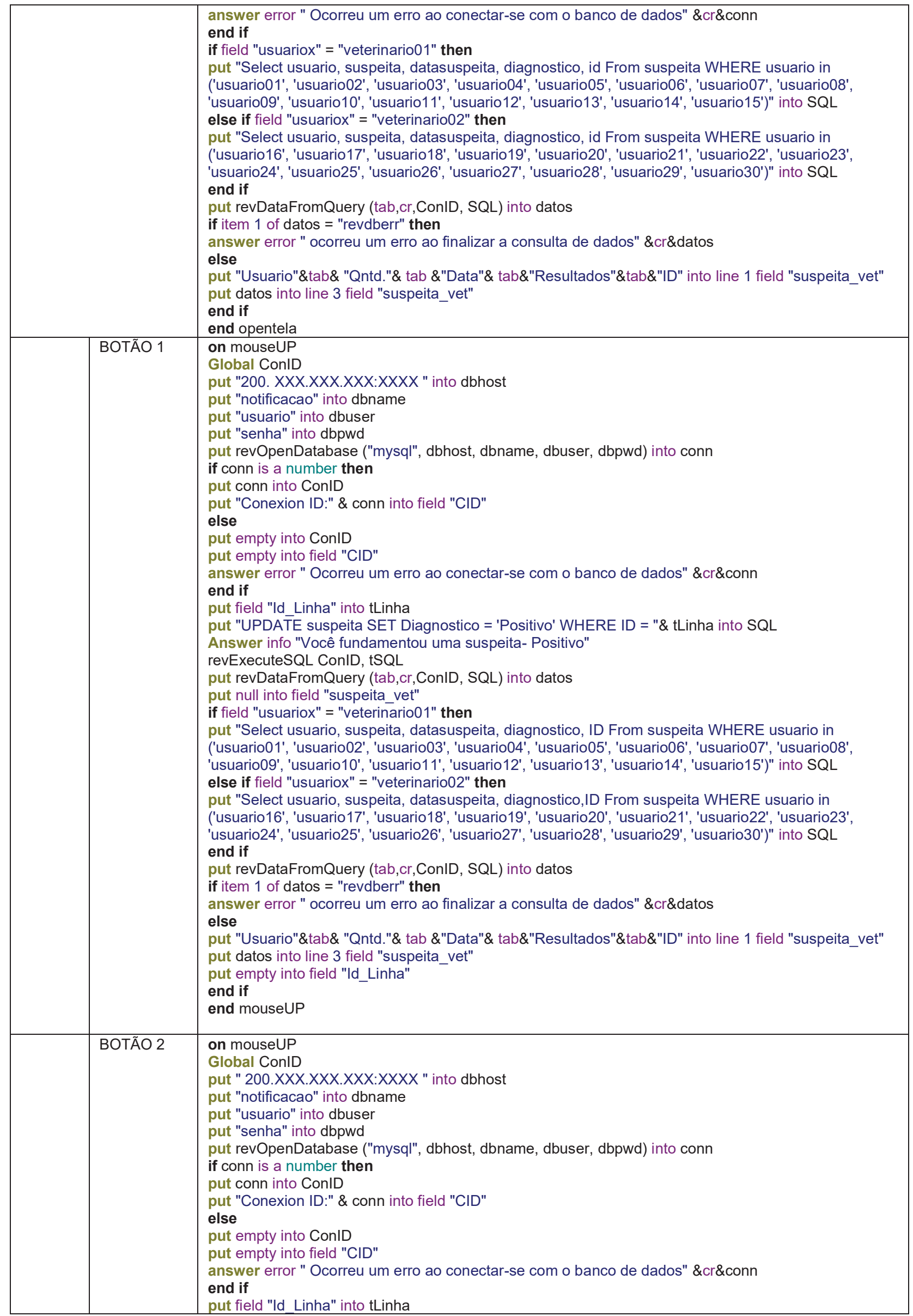




\begin{tabular}{|c|c|c|}
\hline & & $\begin{array}{l}\text { put "UPDATE suspeita SET Diagnostico = 'Negativo' WHERE ID = "\& tLinha into SQL } \\
\text { Answer info "Você fundamentou uma suspeita- Negativo" } \\
\text { revExecuteSQL ConID, tSQL } \\
\text { put revDataFromQuery (tab,cr,ConID, SQL) into datos } \\
\text { put null into field "suspeita_vet" } \\
\text { if field "usuariox" = "veterinario01" then } \\
\text { put "Select usuario, suspeita, datasuspeita, diagnostico, ID From suspeita WHERE usuario in } \\
\text { ('usuario01', 'usuario02', 'usuario03', 'usuario04', 'usuario05', 'usuario06', 'usuario07', 'usuario08', } \\
\text { 'usuario09', 'usuario10', 'usuario11', 'usuario12', 'usuario13', 'usuario14', 'usuario15')" into SQL } \\
\text { else if field "usuariox" = "veterinario02" then } \\
\text { put "Select usuario, suspeita, datasuspeita, diagnostico, ID From suspeita WHERE usuario in } \\
\text { ('usuario16', 'usuario17', 'usuario18', 'usuario19', 'usuario20', 'usuario21', 'usuario22', 'usuario23', } \\
\text { 'usuario24', 'usuario25', 'usuario26', 'usuario27', 'usuario28', 'usuario29', 'usuario30')" into SQL } \\
\text { end if } \\
\text { put revDataFromQuery (tab,cr,ConID, SQL) into datos } \\
\text { if item } 1 \text { of datos = "revdberr" then } \\
\text { answer error " ocorreu um erro ao finalizar a consulta de dados" \&cr\&datos } \\
\text { else } \\
\text { put "Usuario"\&tab\& "Qntd." \& tab \&"Data"\& tab\&"Resultados"\&tab\&"ID" into line } 1 \text { field "suspeita_vet" } \\
\text { put datos into line } 3 \text { field "suspeita_vet" } \\
\text { put empty into field "Id_Linha" } \\
\text { end if } \\
\text { end mouseUP }\end{array}$ \\
\hline & BOTÃO 3 & $\begin{array}{l}\text { on mouseUP } \\
\text { Global ConID } \\
\text { put "200.XXX.XXX.XXX:XXXX" into dbhost } \\
\text { put "notificacao" into dbname } \\
\text { put "usuario" into dbuser } \\
\text { put "senha" into dbpwd } \\
\text { put revOpenDatabase ("mysql", dbhost, dbname, dbuser, dbpwd) into conn } \\
\text { if conn is a number then } \\
\text { put conn into ConID } \\
\text { put "Conexion ID:" \& conn into field "CID" } \\
\text { else } \\
\text { put empty into ConID } \\
\text { put empty into field "CID" } \\
\text { answer error " Ocorreu um erro ao conectar-se com o banco de dados" \&cr\&conn } \\
\text { end if } \\
\text { put field "Id_Linha" into tLinha } \\
\text { put "UPDATE suspeita SET Diagnostico = ' ' WHERE ID = "\& tLinha into SQL } \\
\text { Answer info "Você apagou o statos de uma notificação" } \\
\text { revExecuteSQL ConID, tSQL } \\
\text { put revDataFromQuery (tab,cr,ConID, SQL) into datos } \\
\text { put null into field "suspeita_vet" } \\
\text { if field "usuariox" = "veterinario01" then } \\
\text { put "Select usuario, suspeita, datasuspeita, diagnostico, ID From suspeita WHERE usuario in } \\
\text { ('usuario01', 'usuario02', 'usuario03', 'usuario04', 'usuario05', 'usuario06', 'usuario07', 'usuario08', } \\
\text { 'usuario09', 'usuario10', 'usuario11', 'usuario12', 'usuario13', 'usuario14', 'usuario15')" into SQL } \\
\text { else if field "usuariox" = "veterinario02" then } \\
\text { put "Select usuario, suspeita, datasuspeita, diagnostico,ID From suspeita WHERE usuario in } \\
\text { ('usuario16', 'usuario17', 'usuario18', 'usuario19', 'usuario20', 'usuario21', 'usuario22', 'usuario23', } \\
\text { 'usuario24', 'usuario25', 'usuario26', 'usuario27', 'usuario28', 'usuario29', 'usuario30')" into SQL } \\
\text { end if } \\
\text { put revDataFromQuery (tab,cr,ConID, SQL) into datos } \\
\text { if item } 1 \text { of datos = "revdberr" then } \\
\text { answer error " ocorreu um erro ao finalizar a consulta de dados" \&cr\&datos } \\
\text { else } \\
\text { put "Usuario"\&tab\& "Qntd."\& tab \&"Data"\& tab\&"Resultados"\&tab\&"ID" into line 1 field "suspeita_vet" } \\
\text { put datos into line } 3 \text { field "suspeita_vet" } \\
\text { put empty into field "Id_Linha" } \\
\text { end if } \\
\text { end mouseUP }\end{array}$ \\
\hline TELA 15 & & MAPA GOOGLE \\
\hline
\end{tabular}

Fonte: (RABAQUIM, 2017) 